\title{
Proposta de aclaração do "pacto sucessório" à luz de novos dados
}

Abel Estefânio

\section{OpenEdition}

\section{Journals}

\section{Edição electrónica}

URL: http://journals.openedition.org/medievalista/1401

DOI: 10.4000/medievalista. 1401

ISSN: 1646-740X

\section{Editora}

Instituto de Estudos Medievais - FCSH-UNL

Refêrencia eletrónica

Abel Estefânio, "Proposta de aclaração do "pacto sucessório" à luz de novos dados », Medievalista [Online], 16 | 2014, posto online no dia 11 outubro 2017, consultado no dia 23 abril 2019. URL : http:// journals.openedition.org/medievalista/1401 ; DOI : 10.4000/medievalista.1401

(C) IEM 
Título: Proposta de aclaração do "pacto sucessório" à luz de novos dados Autor: Abel Estefânio

Universidade: Investigador Independente.

Faculdade e Departamento / Unidade de Investigação: Sem filiação institucional.

Código Postal:

Cidade: Porto

País: Portugal

Contacto: aestefanio@hotmail.com

Fonte: Medievalista [Em linha]. Direc. José Mattoso. Lisboa: IEM.

Disponível em: http://www2.fcsh.unl.pt/iem/medievalista/

ISSN: 1646-740X

\section{Data recepção do artigo: 31.Outubro.2013}

\section{Data aceitação do artigo: 17.Janeiro.2014}

\section{Resumo}

Num trabalho anterior publicado na Revista Medievalista online, o autor considerou que o designado "pacto sucessório" entre os condes D. Raimundo e D. Henrique poderia ser um falso moderno, embora não tivesse podido demostrá-lo categoricamente. No presente trabalho é retomado o estudo do pacto pela abordagem do argumento linguístico, que se revelou inconclusivo. Por essa razão, foi necessário dar continuidade à investigação sobre o modo como o pacto chegou às mãos de Luc D'Achery. A descoberta do manuscrito que o monge beneditino da congregação de São Mauro publicou no Spicilegium revelar-se-ia decisivo para o autor rever a sua posição sobre a veracidade histórica do documento, defendendo agora que os seus dados podem se utilizados como base para uma reconstituição histórica credível. Em conformidade, é apresentada uma proposta de datação crítica entre 1105-1107, baseada em elementos 
internos do texto, encurtando significativamente o intervalo anteriormente proposto por Rui Pinto de Azevedo nos Documentos Medievais Portugueses. Por outro lado, a localização e estudo de um documento inédito do conde D. Raimundo veio contribuir para o esclarecimento do contexto em que foi celebrado o pacto.

Palavras-chave: História ibérica, Formação da nacionalidade, Crítica de autenticidade, Cluny, Mauristas.

\section{Abstract}

In an earlier work published in the Medievalista online Journal, the author considered that the designated "pacto sucessório" between the Counts Raymond and Henry could be a modern fake, although he had not been able to say that categorically. In the present paper, it is developed the study of the linguistic argument, which proved to be inconclusive. For this reason, it was necessary to continue the research on how the pact came into the hands of Luc D' Achery. The discovery of the manuscript that the benedictine monk of the congregation of St. Mauro published in the Spicilegium would prove to be decisive for the author to reconsider its position on the historical veracity of the document, arguing now that its data can be used as basis for a credible historical reconstruction. Accordingly, he presents a proposal of critical dating of the famous document between 1105-1107, based on internal elements of the text, significantly shortening the interval previously proposed by Rui Pinto de Azevedo in the Documentos Medievais Portugueses. On the other hand, the location and study of an unpublished document of Count Raymond contributes to clarify the context in which the agreement was concluded.

Keywords: Iberian history, Formation of the nationality, Critique of authenticity, Cluny, Maurists. 


\title{
Proposta de aclaração do "pacto sucessório" à luz de novos dados
}

\author{
Abel Estefânio
}

Todo o começo é involuntário / Deus é o agente. / O herói a si assiste, vário / e inconsciente. / À espada em tuas mãos achada / teu olhar desce. / "Que farei eu com esta espada?" / Ergueste-a, e fez-se.

(«O Conde D. Henrique», Poemas esotéricos, Fernando Pessoa)

Não conheço documento na História Medieval Hispânica que tenha sido tão longamente debatido como o designado "pacto sucessório". Sob a égide do abade Hugo de Cluny, o conde D. Henrique reconhece o conde D. Raimundo como legítimo herdeiro do reino de Leão e Castela. Como recompensa, D. Raimundo promete a D. Henrique o território de Toledo ou da Galiza. Nem sempre os textos que usamos para fazer História são tão significativos como este mas, apesar dos esforços feitos por historiadores de mérito, continua a suscitar opiniões muito diversas por parte da comunidade científica.

Quando o estudei pela primeira vez, pareceu-me que se tratava de um falso histórico e apresentei essa hipótese num artigo publicado em 2011 na revista Medievalista ${ }^{1}$. Admiti, nessa altura, que podia ter sido uma contrafação elaborada pouco depois de 1640 no contexto da restauração da independência portuguesa, para favorecer, implicitamente, a tese da submissão de Portugal a Espanha e demonstrar que todos os reis de Portugal desde Afonso Henriques tinham usurpado um direito da Coroa espanhola. Todavia, como não o pude afirmar categoricamente, não dei o assunto por

\footnotetext{
${ }^{1}$ ESTEFÂNIO, Abel - “O 'pacto sucessório' revisitado: o texto e o contexto". Medievalista [Em linha]. No 10 (Julho de 2011). [Consultado 07.06.2013]. Disponível em: http://www2.fcsh.unl.pt/iem/medievalista/MEDIEVALISTA10 \estefanio1002.html.
}

Medievalista online № 16। Julho - De ze mbro 2014 (C) $\mathbb{E M}$ - Instituto de Estudos Medieva is 3 www2.fc sh.unl.pt/ ie m/me die va lista 
encerrado. Havia, desde logo, que considerar a nota que o Professor José Mattoso elaborou sobre o meu estudo, com o contributo do Professor Arnaldo do Espírito Santo relativamente ao argumento linguístico. Perante a ausência de sinais evidentes do uso de um latim clássico que denuncie um falsário da época moderna, o Diretor da Medievalista considerou que se impunha um exame mais aprofundado.

No presente trabalho, apresento os resultados do meu percurso de investigação ao longo dos dois últimos anos. Na primeira parte, começo por examinar as dúvidas levantadas pela análise linguística do texto, passando pela revisão do que desde então se escreveu a propósito do pacto, até um aprofundamento da investigação sobre o seu aparecimento na época moderna. A descoberta do manuscrito e o estudo da atividade do centro de erudição maurista revelar-se-iam decisivos para rever a minha posição. Defendo agora que o pacto pode ser utilizado como base para uma reconstituição histórica credível. Em conformidade, apresento uma proposta de datação crítica, baseada na crítica interna do texto $^{2}$.

$\mathrm{Na}$ segunda parte do trabalho analiso o papel dos condes na conjuntura leonesacastelhana. São assim estudados os antecedentes que conduziram à realização do pacto, o tempo em que se deve ter concretizado o acordo e as consequências que dele podem ter derivado, num cenário político que rapidamente o tornou caduco.

\section{O "pacto sucessório" (novamente) revisitado}

\subsection{O argumento filológico}

Comecemos então pelo problema filológico levantado pelo Professor Arnaldo do Espírito Santo e que se concentra numa única palavra do texto, o uso de Leon em vez de Legione, o que justificou um exame cuidadoso. Comecei por consultar os Documentos Medievais Portugueses, publicados por Rui Pinto de Azevedo, onde o pacto se encontra

\footnotetext{
${ }^{2}$ Uma síntese desta parte do trabalho foi apresentada numa comunicação ao $5^{\circ}$ Congresso Europeu de Estudos Medievais realizado na Faculdade de Letras da Universidade do Porto, de 25 a 29 de Junho de 2013: "Do segredo ao esquecimento e da descoberta à perda: o que resta do célebre "pacto sucessório'?". in Segredo e descoberta na Idade Média. Programa, resumos e caderno. Porto: Faculdade de Letras da Universidade do Porto, 2013, pp. 105-107.
} 
inserido, tendo verificado que a presença da forma Leon no pacto é singular, pois em outros documentos só temos formas derivadas de Legione ${ }^{3}$. Este primeiro resultado parecia não abonar a forma Leon num documento do conde D. Henrique, ou mesmo do século XII. Mas, como sabemos que o conde D. Henrique confirmou 20 documentos de Afonso VI e o conde D. Raimundo confirmou 39 documentos do mesmo rei, fui também percorrer os documentos desta chancelaria, tendo encontrando apenas três exceções relativamente ao topónimo usual Legione: um falso, um suspeito e um que resulta de uma reformulação posterior ${ }^{4}$. Atente-se, todavia, que na coleção diplomática da Rainha D. Urraca surge um original de 1119 com a forma Leone 5 . Impunha-se também uma pesquisa aos documentos da Abadia de Cluny aos quais o pacto pertence, onde se verifica a predominância das formas derivadas de Legio mas não se exclui a possibilidade de Leon $^{6}$.

Colmatando o facto de aqui no Porto não encontrar os volumes que necessitaria das Fontes da História Leonesa de José Maria Catón, o Professor Ermelindo Portela enviou-me amavelmente a informação que na documentação leonesa se encontra, para Legion, a referência mais antiga no ano 944 e, para Leon, a indicação mais antiga é de

\footnotetext{
${ }^{3}$ AZEVEDO, Rui de (ed.) - Documentos Medievais Portugueses, Documentos Régios. Lisboa: Academia Portuguesa de História, 1958-1962, 2 vol., t. I, DR, doc. 3 de 1096, doc. de 1101, doc. 68 de 1124, doc. 120 de 1131, doc. 288 de 1165 e doc. 279 de 1271.

${ }^{4}$ GAMBRA, Andrès - Alfonso VI, cancillería, cúria e império. 2 vols.. León: Centro de Estudios San Isidoro, 1997, tomo 2: o falso «Pelagius episcopus Leone fiat», doc. 81, datado de 1085 mas em cópia da primeira metade do século XII, o suspeito (Bernard Reilly considerou-o mesmo um falso óbvio): «renante in Toleto et in Leone et in Galizia et tota urbis Castella», doc. 85, datado de 1086 mas em cópia de finais do século XII e a reformulação posterior: «Regnate Adefonsso rege in Toletum et in Leon», doc. 134 de 1095, reformulado em 1148 .

${ }^{5}$ RUIZ ALBI, Irene (ed.) - La Reina Doña Urraca (1109-1126): Cancillería y colleción diplomática. León: Centro de Estudios San Isidoro, 2003, doc. 106: «Regnante regina donna Urraka in Leone et in Castella et in Gallecia».

${ }^{6}$ Uma pesquisa na base de dados em linha Cartae Cluniacenses Electronicae (CCE) dos 5500 diplomas de Cluny (802-1300), da Universidade de Münster (disponível em http://www.unimuenster.de/Fruehmittelalter/Projekte/Cluny/CCE/Welcome-e.htm), revelou os seguintes resultados:

- Formas a partir de Legio (37): Legione (16), Legionem (2), Legionense (1), Legionensem (1), Legionensi (4), Legionensis (12) e Legionis (1).

- Formas a partir de Leone (4): Leonensis (1), Leonum (1), Leone (1) e Leon (1), tal como nos aparece no pacto, mas apenas num documento em castelhano datado de 1286.
} 
9117. Finalmente, num documento particular de 1111 do Mosteiro de Santa Maria de Trianos, descobri «in terra de Leon» ${ }^{8}$.

Estes dados, não sendo exaustivos, permitem-nos desde logo tirar algumas conclusões provisórias. Revelam-nos um cultismo em documentos de chancelaria régia na preferência de Legione e um vulgarismo fora dela nas variantes Leone ou Leon. Segundo Menendez Pidal, a luta pela perda ou conservação do -e final durou vários séculos ${ }^{9}$. Sendo Leon mais raro em documentos latinos anteriores ao século XII, dá-se depois o contrário. Pesando tudo, apenas posso concluir que num pacto para a partilha do reino pelos condes D. Henrique e D. Raimundo fosse mais expectável encontrar Legione mas não é impossível a presença de Leon.

Por outro lado, o Professor Arnaldo do Espírito Santo refere que a tendência de um latinista do séc. XVII seria para escrever terras Legionis ou terras legionenses e que o citado Philippus Prudens de Caramuel Lobkowitz (1639) seria uma exceção. No jogo de palavras que é feito entre o nome do leão animal e o do Reino de Leão, este Autor fez passar a ideia incorreta de que a antiga monarquia da Península Ibérica León deriva de Leo / Leonis e que só mais tarde foi considerado como derivado de Legio / Legionis, o território onde esteve acantonada a Legio Septima Gemina. Contudo, encontrei muitos eruditos do século XVII que, ao referirem-se ao reino de León, escreveram em latim Leonis $^{10}$. O motivo pode ter sido por uma desatenção na retroversão, pois enquanto na

7 FERNANDEZ CATÓN, José Maria - «Index verborum» de la documentación medieval leonesa: Archivo de la Catedral de León (775-1300). León: Centro de Estudios San Isidoro, 2002, tomos III e IV: em 17 de novembro de 944 «de termino de calcata que discurrit ad Legion» e em 1 de abril de 911 «in territorio que cognominantur Leon».

${ }^{8}$ CASTÁN LANASPA, Guillermo; CASTÁN LANASPA, Javier (ed.) - Documentos del Monasterio de Santa Maria de Trianos (siglos XII-XIII). Salamanca: Ediciones Universidad de Salamanca, 1992, doc. 1 de 30 de Junho de 1111, cujo original está bem conservado e legível, mas com algumas roturas que impedem a leitura de algumas palavras: «Episcopus ... in terra de Leon, in sedis Sancte Marie Leonensis» e «Pero Diez mau ... in terra de Leon».

${ }^{9}$ MENÉNDEZ PIDAL, Ramón - Orígenes del español, Estado linguístico de la Península Ibérica hasta el siglo XI. 4ª ed. Madrid: Espasa-Calpe, 1956, pp. 186, 188 e 307.

${ }^{10}$ Alguns exemplos desse equívoco: «filii nostri Castellae, Leonis et Aragonum rex et regina», Bula de Sixto IV, de 16 de Outubro de 1483, in Diario de sesiones de las cortes generales y extraordinárias. Tomo VI. Madrid, 1870, p. 4393,

- «Carolus Dei gratia, rex Castellae, Leonis, Arragoniae» (ESPEN, Zeger Bernard van Commentarius in canones et decreta juris novi et in juris novissimum. Lovanii, 1753, p. 361),

- «Hispaniae Reges Legionis vel Leonis» e «Regum Leonis sive Legionis» (LOPEZ DE PALATIOS RUUIOS, Juan - Repetitio Rvbricae et cap. Per vestras ..., Lvgdvni, 1576, p. 581),

«Alfonso Regi Leonis, Castellam» e «Ferdinando ... Castellae \& Legionis Principi» (BRUGGEN, Joannes Gualtherus del - Vnio divinae et hvmanae domus. Antverpiae, 1669, p. 71), 
língua latina não há equívoco entre o nome do animal leo e o do reino Legio, para o hispânico, León tanto pode ser o rei da selva como o nome do antigo reino. Mas o uso de Leon também pode resultar da confusão entre a designação do reino e o símbolo adotado para as suas armas, o leão ${ }^{11}$.

Em conclusão, o problema do Leon versus Legione levantado pelo Professor Arnaldo do Espírito Santo é deveras interessante e complexo. Tendo recorrido a um estudo de casos, posso concluir não ser viável obter a partir da forma Leon suporte para uma decisão segura sobre o problema da veracidade histórica do pacto. Se a utilização de Leon é possível num documento medieval, não seria menos possível numa falsificação moderna. Mas, dado que o Professor Arnaldo do Espírito Santo não detetou outros elementos no texto que se pudessem considerar suspeitos, é de relaxar a presunção de falsidade, ou seja, que do ponto de vista linguístico é razoável considerar a sua autenticidade. Neste sentido, tornou-se necessário aprofundar a revisão da literatura não só sobre o controverso documento mas também sobre as relações entre os condes borgonheses, o rei Afonso VI e o abade Hugo de Cluny.

\subsection{Opiniões desencontradas}

Tendo o pacto sido publicado, pela primeira vez, pelo beneditino francês Dom Luc D’Achery, em 1659, na sua obra magna, o Spicilegium, e divulgado na península pelo Cardeal Aguirre, em 1694, seguir-se-ia um século de dúvidas ou mesmo negação da sua veracidade $^{12}$. Só a partir de João Pedro Ribeiro é que o documento foi universalmente aceite, embora os historiadores nunca tenham chegado a acordo quanto às condições em que foi produzido, para o que contribui o facto de não se encontrar datado. A situação

«Philipii IV. Titulus fuit: Philippus DEI Gratia Rex Castiliae, Leonis,...» e [de Carlos V] «Rex Germaniae, Castiliae, Aragonum, Legionum, ...» (BACMANN, Johann Christoph - Notitia dignitatum illustrium civilium, sacrarum, eqvestrium. $2^{\mathrm{a}}$ ed., Academia Francofurtana, 1677, pp. 61 e 62).

11 Encontra-se devidamente discriminada em «Alphonsus rex Legionis» e «arma regia mixta sunt ex Castellis \& Leonibus», (SCHOTTUS, Andreas; PISTORIUS, Johann; SCHOTTUS, Franciscus Schottus Hispaniae Illvstratae. Francofvrti, 1603, tomo I, p. 282), mas é natural que nem sempre assim acontecesse.

12 ACHERY, Luc d' - Veterum aliquot scriptorum qui in Galliae bibliothecis, maxime Benedictinorum, latuerant, Spicilegium ... opera et studio D. Lucae d'Acheri [...]. Parisiis: apud C. Savreux., 1659, t. III, pp. 122-123 e AGUIRRE, Joseph Saenz de - Collectio máxima conciliorum omnium Hispaniae et Novi Orbis. Roma: Jacobi Komarek Bohemi, 1694, tomo III, p. 305.

Medievalista online № 16। Julho - De ze mbro 2014 (C) $\mathbb{E M}$ - Instituto de Estudos Medieva is 7 www2.fc sh.unl.pt/ ie m/me die va lista 
manteve-se até meados do século XX e é espelhada no prudente intervalo crítico apontado pelo diplomatista Rui Pinto de Azevedo, abarcando treze anos. A polémica em torno do pacto pareceu acalmar um pouco com a publicação, em 1971, de um artigo do historiador americano Charles Julian Bishko. Este Autor, que estudou em profundidade as relações de Cluny com a Península Ibérica, atribuiu a realização do pacto ao ano de 1105, o que foi aceite por um número significativo de historiadores ${ }^{13}$. A primeira dissensão de peso veio de Bernard Reilly. Este autor, que estudou praticamente toda a documentação hispânica relativa ao reinado de Afonso VI, admitiu que o pacto tivesse sido celebrado dez anos antes da data proposta por Bishko ${ }^{14}$. Embora não lhe encontremos seguidores diretos, parece que o seu contributo teve o efeito de reacender a polémica. Entrando na primeira década do século XXI, vemos dois historiadores espanhóis, primeiro Gonzalo Martínez Diez e depois Ermelindo Portela, a admitirem a possibilidade de o pacto ter sido produzido em 1096 ou $1097^{15}$. Esta era, no essencial, a informação que possuía quando publiquei o meu artigo em 2011.

Só posteriormente é que dei conta que um ano antes tinham sido publicados dois artigos com opiniões divergentes sobre a datação crítica do pacto, num mesmo volume da revista argentina Estudios de História de España. Um deles é da autoria de István Szászdi León-Borja e Vitaline Correia de Lacerda ${ }^{16}$. Estes coautores, que dedicam a sua atenção ao papel do conde D. Henrique como inspirador da política separatista que fez do condado portucalense um reino reconhecido da Europa cristã, apresentam uma interpretação audaciosa, considerando que o pacto foi elaborado, assinado e arquivado em solo da Borgonha, com o acordo e a conivência do abade Hugo de Cluny e do duque Eudes Borel. Neste contexto, atribuem-lhe uma data anterior a 1094, antes do

13 BISHKO, Charles Julian - "Count Henrique of Portugal, Cluny and the antecedents of the «Pacto Sucessório»”. in Revista Portuguesa de História. 13 (1971), pp. 155-188. Reedição com nota adicional in Spanish and portuguese monastic history: 600-1300. London, Variorum Reprints, 1984, IX, pp. 166-167. ${ }^{14}$ REILLY, Bernard F. - The Kingdom of León-Castilha under King Alfonso VI, 1065-1109. Princeton: Princeton University Press, 1988, p. 252.

${ }^{15}$ MARTÍNEZ DÍEZ, Gonzalo - Alfonso VI, señor del Cid, conquistador de Toledo. Madrid:Temas de Hoy, 2003, p.170 e PORTELA SILVA, Ermelindo - Galicia después del reino de Galicia. Conferência apresentada ao Colóquio D. Afonso Henriques: em torno da criação e consolidação das monarquias do ocidente Europeu (Faculdade de Letras de Lisboa, 14-16 de Dezembro de 2009). Texto cedido amavelmente pelo autor.

16 SZÁSZDI LEÓN-BORJA, István; LACERDA, Vitaline Correia de - "El Conde de Portugal D. Henrique: ambición y lealtad". [em linha]. Estudios de Historia de España, 12(2), 2010, pp. $527-528$ e nota 19. [Consultado 29.09. 2012]. Disponível em: http://bibliotecadigital.uca.edu.ar/repositorio/revistas/conde-portugal-henrique-ambicion-lealtad.pdf.

Medievalista online № 16। Julho - De ze mbro 2014 (C) $\mathbb{E M}$ - Instituto de Estudos Medieva is 8 www2.fc sh.unl.pt/ie m/me die va lista 
casamento de D. Henrique com D. Teresa e, portanto, antes do conde receber a Terra Portucalense do seu sogro Afonso VI. O outro estudo publicado na mesma revista é de Júlia Montenegro. Sendo professora na Universidade de Valladolid, tal como István Szászdi, tem uma opinião muito diferente. Depois de analisar algumas questões relativas ao problema sucessório, considera impossível que o pacto se tenha realizado em 1093 e associa-se aos historiadores que o situam na parte final do reinado de Afonso VI, mais concretamente em $1106^{17}$.

Um estudo posterior de Armando Martins, apesar de valorizar alguns aspetos inovadores do trabalho de Júlia Montenegro, que revelam a deterioração das relações entre o rei e o abade a partir de 1080, considera, como mais provável, que o pacto se tenha realizado em 1103 ou $1105^{18}$.

Last but not the least, refira-se a recente biografia de D. Teresa, dos Professores Luís Carlos Amaral e Mário Barroca ${ }^{19}$. Aguardava com elevada expectativa o seu lançamento, não só por ser o primeiro trabalho a levar em conta o meu artigo sobre o pacto, mas também pelo reconhecido mérito dos dois investigadores, o que me levou a evitar concluir o presente trabalho antes de conhecer a sua obra. Inserida numa coleção direcionada para um público amplo, não deixa por isso de ser muito rigorosa na identificação das fontes. Também, no que se refere a estudos, representa o «estado da arte», com a inclusão na bibliografia de mais de meia centena de trabalhos publicados desde o ano 2000. Constitui assim um imprescindível guião para quem pretender estudar o período do segundo condado portucalense e veio facilitar em muito o meu trabalho. No que respeita ao pacto, estes Autores subscrevem a interpretação de Charles Bishko, considerando que em 1105 estavam reunidas as condições para ele se realizar ${ }^{20}$. Em resumo, mantem-se bem acesa a polémica em torno da datação crítica do pacto, com

\footnotetext{
${ }^{17}$ MONTENEGRO, Julia - "La crisis sucesoria en las postrimerías del reinado de Alfonso VI de León y Castilla: el partido Borgoñón" [em linha], Estudios de Historia de España, 12(2), 2010. Vd. p. 376, nota 16 e p. 385. [Consultado 29.09.2012]. Disponível em:

http://bibliotecadigital.uca.edu.ar/repositorio/revistas/crisis-sucesoria-postrimerias-reinado-alfonso.pdf.

18 MARTINS, Armando - "Cluny e a formação de Portugal". in A Idade Média Portugusesa e o Brasil: reminiscências, transformações, ressignificações. Porto Alegre: Vidráguas, 2011, pp. 79-92 e, em especial, a p. 89.

19 AMARAL, Luís Carlos; BARROCA, Mário Jorge - A condessa-rainha Teresa. S.1.: Círculo de Leitores, 2012.

${ }^{20}$ Ibid., p. 159 , nota 3.
} 
propostas recentes que medeiam entre os anos de 1093 ou 1094, 1096 ou 1097, 1103, 1105 ou 1106.

\subsection{O testemunho manuscrito}

Ao longo desta investigação alimentei sempre a esperança que ainda pudesse encontrar o manuscrito do pacto que foi publicado por Luc d'Achery. La Barre, na edição de 1723, acrescentou uma nota marginal informando que os nomes dos condes e do rei estavam referidos por siglas no manuscrito que serviu de base à primeira edição ${ }^{21}$. Depois de La Barre, nenhum outro autor se referiu a esse manuscrito. Na monumental coleção dos documentos de Cluny, o pacto aparece registado de forma abreviada, citado do Spicilegium, sem cota arquivista, como é norma desta coleção diplomática ${ }^{22}$. Por essa razão, Rui de Azevedo considerou improvável que no fundo cluniacense se conservasse ainda o texto aproveitado por d'Achery. Apesar disso, continuei a minha pesquisa no sítio da Gallica, onde a Biblioteca Nacional de França tem vindo a colocar online muita documentação. Foi com grande júbilo, como se pode calcular, que encontrei a tradição manuscrita do pacto usada por Luc d'Achery. Consta de um volume de 583 folhas de papel, formando um in-folio, contendo cópias de cartulários e originais da Abadia de Cluny, em parte da mão de Etienne Baluze e outras colecionadas por ele $^{23}$. O fólio que nos interessa é o que tem o número 470 e o pacto ocupa apenas o lado frente. No canto superior esquerdo tem uma menção à obra onde foi pela primeira vez

\footnotetext{
${ }^{21}$ ACHERY, Luc d' - Spicilegium sive collectio veterum aliquot scriptorum qui in galliae bibliothecis delituerant. Cura L. F. J. de la Barre (ed.), Paris: apud Franc. Montalant, 1723, t. III, p. 418: «In exemplari quo usus est Dacherius, nomina horum Comitum et Regis signantur tantum per primas litteras»». Rui de Azevedo (AZEVEDO, Rui de - Documentos Medievais Portugueses, Documentos Régios. II, nota II, pp. 547-553) transcreve esta nota, mas não a comenta. O único comentário relativo a essa nota que encontrei, ainda que colocado de forma despiciente, foi o feito por Frei Manuel de Figueiredo (FIGUEIREDO, Manuel de - Origem verdadeira do conde D. Henrique. Lisboa: Oficina Patriarcal de Francisco Luiz Ameno, 1789, p. 35, nota 2): «... as iniciais H. e R. ..., ainda que fosse verdadeiro o documento, tanto podia dizer Raymundo de Tolosa, como de Galliza».

22 BRUEL, Alexandre; BERNARD, Auguste (ed.) - Recueil des chartes de l'abbaye de Cluny. Paris : Imprimerie Nationale, 1894, t. V, p. 27, $\mathrm{n}^{\circ} 3673$.

23 Recueil de Chartes de Cluny [Em linha], Bibliothèque Nationale de France, Département des manuscrits, Coleção Baluze $n^{\circ} 86$, f. 470, (12/03/2012). [Consultado 07.06.2013]. Disponível em: http://gallica.bnf.fr/ark:/12148/btv1b9001316h/f335.image.r=chartes\%20cluny.langPT.
}

Medievalista online № 16। Julho - De ze mbro 2014 (C) $\mathbb{E M}$ - Instituto de Estudos Me dieva is 10 www2.fc sh.unl.pt/ ie m/me die va lista 
impresso $^{24}$. Segue-se o texto que conhecemos (vd. Anexo I), com algumas diferenças relativas às versões impressas, embora sejam pouco significativas ${ }^{25}$. A única que importa aqui relevar é, precisamente, a que diz respeito ao nome dos condes e do rei, que são referidos apenas por siglas ${ }^{26}$.

Uma nota de rodapé, em francês, informa-nos que o autor da transcrição não conseguiu identificar o rei nem os seus genros e deixa expressa a sua estupefação pela pretensão de condes aspirarem a transformar-se em reis, não alcançando o tempo histórico em que tal facto pudesse ter ocorrido ${ }^{27}$. Na verdade, teremos de recuar até ao século XI, para encontrar uma epístola de Gregório VII, datada de 28 de junho de 1077, em que o Papa se dirige simultaneamente a reis e condes, implicando a ausência de uma hierarquia entre essas categorias nos termos em que se viria a fixar mais tarde ${ }^{28}$. Esta conjuntura irrepetível na história é a mesma a que pertence o pacto, onde efetivamente um conde se propõe suceder a um rei.

O desdobramento das iniciais dos nomes dos condes e do rei só apareceu na edição impressa, sem que se identificasse a operação como atualmente se exige nos trabalhos

24 «Edita to. 3. Spicilegii pag. 122.».

${ }^{25} \mathrm{O}$ passo impresso «atque adquirere praeparatus occurram» resulta de uma correção erudita da expressão menos elegante do manuscrito «atque occurrere praeparatus occurram». Também, por consulta do manuscrito e da edição de 1659, foi possível confirmar que o erro em «conjucti» em vez do correto «conjuncti» apontado por Rui de Azevedo, apenas acontece na edição de 1723. Por sua vez, Rui de Azevedo omite o «ejus» na expresão «Henricus Comes ejus familiaris», que consta tanto no manuscrito como nas edições de 1659 e 1723. O abade Hugo aparece no manuscrito com o vocativo «Karissime», tendo o «K» sido substituído por «C» em todas as versões impressas.

${ }^{26} \mathrm{Na}$ primeira vez em que é nomeado, Afonso VI, aparece identificado pelas iniciais «AL» e nas vezes seguintes com as iniciais «IL». Na edição de 1659 estas iniciais foram sempre substituídas por «Ildephonsi» (com «ph»), enquanto na edição de 1723 temos na primeira vez «Aldefonsi» (com «f») e nas seguintes «Aldephonsi» (com «ph») (ACHERY, Luc d' - Spicilegium. 1723, t. III, p. 418). No desdobramento do nome do rei Afonso evidencia-se uma intervenção moderna, na opção pelo grupo «ph» em vez do medieval «f», segundo a lição de A. Bruel (BRUEL, Alexandre; BERNARD, Auguste (ed.) Recueil des chartes de l'abbaye de Cluny. Paris: Imprimerie Nationale, 1894, t. V, doc. 4072, pp. 423425). Note-se que «Alfonsus» é já, por si, uma abreviação hispânica de «Ildefonsus» e que o pacto não é o único documento em que as duas formas se encontram em diferentes lugares do mesmo texto (PALlARES, Maria del Carmen; PORTELA, Ermelindo - La reina Urraca. San Sebastián: Editorial Nerea, 2006, p. 195, nota 91: «... regem Ildefonsus de Aragona. ... rex Aldefonsus de Aragon ...»). Por sua vez, os condes Henrique e Raimundo aparecem no manuscrito apenas pelas iniciais «H» e «R», respetivamente.

27 «Il ny a pas encore longtemps que les Roys de Castella ne rapelloyent que comtes Castella».

${ }^{28}$ MONTENEGRO, Julia - "La alianza de Alfonso VI com Cluny y la abolición del rito mozárabe en los reinos de León y Castilla: una nueva valoración”. in Iacobus: revista de estúdios jacobeos y mediavales. Sahagún, no 25-26 (2009), p. 50: «regibus, comitibus, ceterisque principibus Hyspanie». 
paleográficos, pela colocação de parênteses $\operatorname{retos}^{29}$. De qualquer forma, todos os autores que mostraram confiança na autenticidade do pacto, grupo no qual também agora me passo a incluir, aceitaram a identificação dos intervenientes, proposta pelo seu primeiro editor.

Logo a seguir à transcrição do texto do pacto, uma frase latina informa que o documento foi recolhido numa lixeira entre outros documentos valiosos, ali lançados por ignorantes que não sabiam interpretar o seu valor ${ }^{30}$. Segue-se o nome (que penso ser a assinatura) de Anselme Le Michel e a menção ao ano de $1645^{31}$. Este religioso beneditino da congregação de São Mauro e pilar da primeira erudição maurista foi responsável pela constituição de um corpo histórico da Ordem de São Bento e, em particular da Ordem de Cluny, em França. Ele fez um reconhecimento muito completo das bibliotecas e dos arquivos de um grande número de mosteiros. As suas notas, depois de servirem de base aos trabalhos de D'Achery, de Mabillon, de Sainte-Marthe e de tantos outros, são ainda uma mina abundante de informação sobre a história e a literatura da Idade Média ${ }^{32}$. As transcrições de documentos efetuadas por Anselme Le Michel são consideradas de muito boa qualidade do ponto de vista da restituição do texto ${ }^{33}$.

Em 1645, Dom Anselme Le Michel visitou a biblioteca de Cluny e encontrou-a ao abandono, tendo copiado muitos diplomas e tomado muitas anotações dos manuscritos ${ }^{34}$. O pacto, ainda que não esteja expressamente referido, deve ter sido incluído no rol dos documentos que tentou, sem sucesso, transportar da abadia de Cluny à de Saint-Germain-des-Prés, os quais, na sua maior parte, estão desaparecidos ${ }^{35}$. O sucedido, embora não esteja muito claro, envolve o seu assistente Robert Jamet,

\footnotetext{
29 À versão impressa foi ainda acrescentado o título «RAIMVNDI Gallæciæ, \& HENRICI Portugalliæ Comitum, HVGNI Abbati Cluniacensi» e a nota «Mittūt exēplar fœederis amicitiæ inter se initæ, \& pactorum de partienda successione soceri sui Alphonsi, Castellæ ac Legionis Regis».

${ }^{30}$ «Apud cluniacum collegit ex sterquilinio in quod cum alys huiusmodi sacrosanctae vetustatis reliquiis magno numero, fuerat proiectum ab imperitis».

31 «f[rater] Anselmus Le Michel anno 1645».

32 DELISLE, Léopold Victor - Le cabinet des manuscrits de la Bibliothèque impériale. Hildesheim : G. Olms, 1868, volume 2, p. 138.

${ }^{33}$ NOIZET, Hélène - "La transmission de la documentation diplomatique de Saint-Martin de Tours antérieure à 1150". in Histoire et archives. 17 (2005), pp. 7-36.

${ }^{34}$ STRATFORD, Neil - "Jean Mabillon et Cluny”. in Comptes-rendus des séances de l'Académie des Inscriptions et Belles-Lettres. Vol. 151, no 4 (23 de novembro de 2007), pp. 1597-1604 e p. 1780.

35 GASNAULT, Pierre - "Dom Anselme Le Michel et les manuscrits de l'abbaye de Cluny". in Bibliothèque de l'École des Chartes. Vol. CXXXI, no 1 (1973) pp. 209-219; DELISLE, Léopold Inventaire des manuscrits de la Bibliothèque Nationale. Fonds de Cluny. Paris : H. Champion, 1884, pp. 383-396.
}

Medievalista online № 16। Julho - De ze mbro 2014 (C) $\mathbb{E M}$ - Instituto de Estudos Me dievais 12 www2.fc sh.unl.pt/ ie m/me die va lista 
acusado de roubo dos documentos ${ }^{36}$. Anselme Le Michel deve ter morrido pouco tempo depois, em data que se desconhece. Quando Luc d'Achery publicou o pacto em 1659, não teria outra informação do documento para além do fólio que agora encontrei.

Estas informações, associadas à ausência de indícios linguísticos que traíssem um falsário erudito do século XVII, levaram-me a reconsiderar a minha posição sobre o pacto. Ao considerar, agora, que se trata de um documento histórico verídico, impõe-se uma abordagem do problema da sua datação crítica.

\subsection{A data crítica}

Apesar de Rui de Azevedo ter atribuído ao pacto um intervalo de datação crítica extraordinariamente largo, entre a chegada do conde D. Henrique à península em $1095 \mathrm{e}$ a morte do conde D. Raimundo em 1107, vimos que, num trabalho recente, István Szászdi León-Borja e Vitaline Correia de Lacerda propuseram uma data anterior ao seu limite inferior. Por serem autores respeitáveis, poderíamos ser tentados a dilatar ainda mais o intervalo crítico proposto por Rui de Azevedo. Creio, contudo, que a carta que antecede o texto do pacto propriamente dito, contém um pormenor, até aqui descurado, que permite restringir significativamente o intervalo de datação crítica. Depois de se identificar o destinatário - «Domino atque Reverentissimo Cluniacensi Abbati Hugoni, omnique beati Petri Congregationi» - nela se refere os remetentes: «R[aimundus] Comes eiusque filius [Alfonsus Raimundi], et $\mathrm{H}$ [enricus] Comes eius familiaris».

João Pedro Ribeiro viu nas referências a «filius» e a «familiaris», atribuições protocolares diferenciadoras de Raimundo e Henrique perante o abade Hugo ${ }^{37}$. Apesar de a sua argumentação ter sido aceite por quase todos os historiadores, alguns não deixaram de mostrar alguma perplexidade perante tais designações. Como nos refere Charles Bishko, não se encontram razões para o hipotético tratamento protocolar que

${ }^{36}$ BARRET, Sébastien - La mémoire et l'écrit: l'abbaye de Cluny et ses archives (Xe-XVIIIe siècle). Münster : Lit, 2004, p. 27.

${ }^{37}$ RIBEIRO, João Pedro - Dissertações Cronológicas e críticas. Lisboa: Academia Real das Sciencias de Lisboa, 1857, t. III, pp. 45-48 ( $1^{\mathrm{a}}$ ed. 1813). 
Raimundo se assaca perante Cluny ${ }^{38}$. Mais recentemente, Armando Martins, refere também «a desconcertante titulação que os dois condes se atribuem» ${ }^{39}$. Na minha opinião, a interpretação deste passo do texto tem sido prejudicada pela sua pesada herança historiográfica.

Comecemos pelo termo «familiar». Não me parece que se deva entender aqui como um estatuto de Henrique resultante das suas ações beneméritas perante Cluny. Parece-me mais razoável entender familiar como sinónimo de parente. Os autores da recente biografia de D. Teresa esclarecem as dúvidas que existiam sobre o parentesco dos condes, identificando-os como primos afastados, pelo que o termo me parece adequado $^{40}$.

Também não se pode reconhecer «filho» como um estatuto especial de Raimundo perante Cluny, que nunca o teve, e nem mesmo uma leitura atenta do texto latino o permite $^{41}$. Para figurar com o sentido de filho espiritual do abade Hugo, exigiria também uma retórica que não se encontra aqui presente ${ }^{42}$. Tratar-se-á, pois, de uma referência ao filho de Raimundo, D. Afonso Raimundes, opinião partilhada pelos autores da monografia da condessa-rainha ${ }^{43}$. Não vejo razão para suspeitar de um eventual problema de transmissão textual, apesar de o menino não ter completado três

38 BISHKO, Charles Julian - "Count Henrique of Portugal, Cluny and the antecedents of the «Pacto Sucessório»". in Revista Portuguesa de História. 13 (1971), p. 180.

${ }^{39}$ MARTINS, Armando - "Cluny e a formação de Portugal". in A Idade Média Portugusesa e o Brasil: reminiscências, transformações, ressignificações. Porto Alegre: Vidráguas, 2011, p. 88.

${ }^{40}$ AMARAL, Luís Carlos; BARROCA, Mário Jorge - op. cit., pp. 50-51.

41 «Raimundus Comes eiusque filius», que se deve ler «o conde D. Raimundo e seu filho». O Padre Enrique Flórez (FLÓREZ, Enrique - Memorias de las reynas catholicas. Madrid: en la oficina de la viuda de Marin, 1790, t. I, pp. 234-235) duvidou da legitimidade deste pacto, que teve conhecimento pela edição do Cardeal Aguirre, considerando que «vemos allí à Don Ramon mencionando à su hijo», não entendendo de que filho se tratava, pois que o único conhecido, Afonso Raimundes, só nasceu em 1105 e o pacto aparece nessa edição datado de 1093.

42 Veja-se, por exemplo, as duas cartas que o imperador do Sacro Império Romano-Germânico Henrique IV escreveu em 1106, quiçá o ano do pacto, ao seu «queridíssimo pai» o abade Hugo de Cluny, pedindo as suas orações e a sua interseção na disputa que tinha com a Santa Sé: «H[enricus], Dei gratia Romanorum imperator augustus, clarissimo atque dilectissimo p[atr]i H[ugoni] et universis sanctis fratribus Cluniacensis cenobii dulcem filii affectum ac devotum fratris, immo servi obsequium...» (Paris, $\mathrm{BNF}$, lat. $\left.11826 \mathrm{n}^{\circ} 4\right) \mathrm{e}$ «H[enricus], Dei gratia Romanorum imperator augustus, U[goni], venerabili Cluniacensi abbati, quicquid licet peccator, tamen spiritalis filius devotius et humilius suo desiderantissimo et dilecto spiritali patri...» (Paris, BNF, lat. $11826 \mathrm{n}^{\circ} 7$ ).

${ }^{43}$ Veja-se a tradução do latim para português do texto do pacto feita pelo Prof. Doutor Manuel Francisco Ramos, em AMARAL, Luís Carlos; BARROCA, Mário Jorge - op. cit., pp. 331-332. 
anos quando o pai morreu ${ }^{44}$. Na verdade, é normal os diplomas medievais aludirem a filhos menores. Como se pode ver no documento, a referência ao filho é protocolar, aparecendo apenas no texto da carta que antecede o pacto propriamente dito. Assente que se trata de uma referência ao futuro Afonso VII de Leão e Castela, ela marca o terminus a quo do pacto a 1 de março de $1105^{45}$. O terminus ad quem mantém-se na data em que faleceu o conde D. Raimundo, que deve ter sido a 20 de setembro de $1107^{46}$.

É verdade que este intervalo temporal já tinha sido proposto pelo sábio medievalista Pierre David há sessenta e cinco anos atrás ${ }^{47}$. Mas ao retomá-lo, fizemo-lo numa base nova, a partir da crítica interna do texto. Por outro lado, se até aqui já existia um amplo consenso de que o pacto visava afastar Sancho da sucessão de Afonso VI, podemos agora acrescentar que o nascimento de Afonso Raimundes foi o trigger para a sua realização. Creio, pois, que encontrei o motivo a que Andrès Gambra alude para congregar os condes na realização do pacto $^{48}$. Seria na sequência de tão auspicioso evento, que se realizaria o acordo amigável entre os dois principais membros do «partido» pró-francês ${ }^{49}$.

\section{O significado do pacto na conjuntura leonesa-castelhana}

\footnotetext{
${ }^{44}$ FLÓREZ, Enrique - España sagrada. Madrid: M. F. Rodriguez, 1766. Vol. 20: História Compostelana, cap. 46, p. 95 «Hic Rex cum ejus generum Consulem Raimundum à visione praesentis lucis fata funditos subduxissent, \& ejus filius, qui adhuc trienii tempus nequaquam expleverat,...».

45 Conf. REILLY, Bernard F. - The Kingdom of León-Castella under Queen Urraca (1109-1126). Princeton: Princeton University Press, 1982p. 45, nota 2: Os «Anales toledanos» referem a sua data de nascimento a 1 de Março de 1106 (HUICI MIRANDA, Ambrosio (ed.) - Las crónicas latinas de la reconquista. 2 vols. Valencia: Estab. Tip. Hijos de F. Vives Mora, 1913, vol. 1, p. 344); FLÓREZ, Enrique - Memorias de las reynas catholicas de España. Madrid: por Antonio Marín, 1761, tomo 1, pp. 234-235, corrige a data para 1105; esta data é seguida por SÁNCHEZ BELDA, L. (ed.) - Chronica Adefonsi Imperatoris. Madrid: CSIC, 1950, p. 5, n. 2. Mais recentemente, a data foi aceite por AMARAL, Luís Carlos; BARROCA, Mário Jorge - op. cit., p. 372.

${ }^{46}$ AMARAL, Luís Carlos; BARROCA, Mário Jorge - op. cit., p. 50.

${ }^{47}$ DAVID, Pierre - "Le pacte succéssoral entre Raymond de Gallice et Henri de Portugal". in Bulletin Hispanique. Bordeaux: Faculte dês Lettres, tomo L (1948), p. 290.

48 GAMBRA, Andrès - op. cit., tomo 1, p. 437: «Aquellos personajes debieron formar en el marco 'Palatium regis' un clan restringido, con intereses familiares y políticos bien diferenciados y dispuestos, llegado el caso, a apoyarse mutuamente según se deduce del enigmático texto conocido como el 'pacto sucessório'».

49 A sugestiva expressão é do Professor José Mattoso (MATTOSO, José - D. Afonso Henriques. Lisboa: Temas e Debates, 2007, p. 31) e de algum modo seguida por Júlia MONTENEGRO no título do seu artigo "La crisis sucesoria en las postrimerías del reinado de Alfonso VI de León y Castilla: el partido Borgoñón" (in Estudios de Historia de España. Vol. XII, Tomo 2, 2010, pp. 369-388).
} 


\subsection{Os antecedentes que levaram à sua realização}

Importa aqui recordar que o pacto procura antecipar o cenário político que deveria suceder ao desaparecimento de Afonso VI. O processo relativo à sucessão teria ficado inquinado quando, depois da morte da rainha D. Constança, em 1093, ou provavelmente ainda em vida desta, a princesa muçulmana Zaida tornou-se «amiga» de Afonso VI, e teve dele o infante D. Sancho. Com o posterior casamento do rei com Zaida, em maio de 1100, convertida ao cristianismo e batizada com o nome de Isabel, estava dado o primeiro passo para que o monarca viesse a escolher Sancho como seu sucessor ${ }^{50}$. Mais tarde ou mais cedo, os dois condes resolveram conspirar contra essa situação. Não fosse a datação crítica interna que nos proporciona o texto do pacto e poderíamos remontar a sua realização a esse ano de 1100 ou, então, a 1103, quando Sancho começa a confirmar diplomas do seu pai ${ }^{51}$. Mas como entendo que a referência ao filho de Raimundo no texto da carta que antecede o pacto não permite datá-lo antes de 1105, haverá que dar uma atenção especial à proposta de Charles Bishko. Este Autor considerou que o pacto foi firmado entre 14 de maio e 22 de setembro de 1105. Apesar de numa nota, que acrescentou posteriormente na reedição do seu trabalho, ter admitido que houve erro na datação do documento que se refere à primeira das datas, Bishko manteve, no essencial, a sua datação crítica, no que foi seguido, talvez de forma inadvertida, por muitos historiadores. Se não, vejamos. Bishko considerou que o pacto não se podia ter realizado em 1106, por o conde D. Raimundo já estar doente e por não encontrar evidência de o conde D. Henrique se encontrar fora do seu condado, o que não tem suporte face às fontes que foram publicadas após o seu trabalho, que mostram claramente que D. Raimundo não deixou de confirmar documentos até ao mês em que morreu e que em muitas dessas ocasiões o faz juntamente com D. Henrique em

\footnotetext{
${ }^{50}$ É pela autoridade do Bispo Paio de Oviedo que somos informado de Zaida que «babtizata Helisabeth fuit vocitata» (SÁNCHEZ ALONSO, Benito (ed.) - Crónica del Obispo Don Pelayo. Madrid: Imprenta de los Sucesores de Hernando, 1924, p. 87). A rainha Isabel, que aparece mencionada em documentação régia fiável entre 1101 e 1107, seria realmente a princesa Zaida, mãe de Sancho Alfónsez (AMARAL, Luís Carlos e Mário Barroca, op. cit., p. 58).

${ }^{51}$ GAMBRA, Andrès - op. cit., tomo 2, Docs.: 169 ([1102-1103], janeiro, 17), 170 (1103, janeiro, 25), 171 (1103, fevereiro, 10), 173 (1103, maço, 23), 174 ([1103], abril, 23, suspeito), 175 (1103, maio, 6), 176 (1103, junho, 22), 178 ([1103], dezembro, 12).
}

Medievalista online № 16 । Julho - De ze mbro $2014 \odot \mathbb{E}$ - Instituto de Estudos Medievais 16 www2.fc sh.unl.p $\mathrm{t} / \mathrm{ie} \mathrm{m} / \mathrm{me}$ die va lista 
Sahagún, o local favorito de permanência da corte ${ }^{52}$. Bishko considerou também que no ano de 1107 não se podia ter realizado o pacto, por Dalmácio Geret se encontrar na Borgonha por volta de 13 de agosto de 1107. Na verdade, o documento que o coloca em Berzé foi primeiramente publicado com data de «antes de 13 de agosto», sendo posteriormente datado entre 22 de fevereiro e 13 de agosto, pelo que não se pode excluir que, em 1107, o camareiro cluniacense pudesse vir a Espanha com a incumbência de promover o pacto, ainda que se admita que a sua viagem se realizasse preferencialmente nos meses de primavera e verão ${ }^{53}$. Dito isto, mesmo que aceitasse as razões apresentadas por Bishko para a realização do pacto, elas não permitem afastar a possibilidade de a sua realização ter ocorrido em 1106 ou 1107.

Não deixo, no entanto, de considerar muito frágil a reconstituição feita por Charles Bishko. Este Autor considera que o pacto reflete um antagonismo entre os dois condes borgonheses, ao mesmo tempo que reconhece que, para além do pacto, o papel do conde D. Henrique na crise sucessória é apenas conjetural e que a sua opinião contraria algumas autoridades como o Cardeal Saraiva, Alexandre Herculano, Pierre David e Rui de Azevedo ${ }^{54}$. Para Bishko, a elevada concentração de portugueses na doação ao mosteiro de Santo Isidro de Duenas de 30 de janeiro de 1105, seria um indício de um ato de conspiração para se posicionar como herdeiro de Afonso VI, em confrontação direta, tanto com as pretensões do rei relativas ao seu filho Sancho, como com as de Raimundo. O documento em causa é uma cartula testamenti feita por sufrágio das suas

52 Entre 1105 e 1107, os dois condes encontram-se a confirmar documentos num número muito significativo de ocasiões. Sem pretender ser exaustivo, refira-se cinco documentos da chancelaria de Afonso VI e dezassete documentos do Mosteiro de Sahagún, respetivamente: GAMBRA, Andrès - op. cit., tomo 2: 183 (1105, junho, 1), 184 (1105, setembro, 22), 185 (1106, março, 19), 188 (1107, maio, 8), 189 (1107, maio, 14); HERRERO DE LA FUENTE, Marta (ed.) - Colección Diplomática del Monasterio de Sahagún. Tomo III. Leon: Centro de Estudios e Investigacion San Isidoro, 1988: 1123 (1105, junho), 1124 (1105, junho, 2), 1127 (1105, setembro, 11), 1128 (1105, dezembro, 13), 1129 (1105, dezembro, 13), 1132 (1106, janeiro, 10), 1133 (1106, janeiro, 12), 1134 (1106, janeiro, 16), 1135 (1106, janeiro, 22), 1137 (1106, fevereiro, 19), 1139 (1106, março, 4), 1145 (1106, junho, 10), 1149 (1106, novembro, 7), 1150 (1107, janeiro, 18), 1153 (1107, junho, 12), 1154 (1107, julho, 27), 1156 (1107, agosto, 7) e 1157 (1107, agosto, 27).

53 BRUEL, Alexandre; BERNARD, Auguste (ed.) - Recueil des chartes de l'abbaye de Cluny. Tomo V, 1894, doc. 3862: «1107, avant le 13 août». DAVID, Pierre - "Le pacte successoral entre Raymond de Galice et Henri de Portugal". in Bulletin Hispanique. Tomo 50, n³-4 (1948), p. 284, nota 4 refere que Dalmácio Geret se encontra em Berzé a confirmar um diploma de Guilherme II de Mâcon, datado do oitavo ano do papa Pascal II, sendo que o nono ano começou a 13 de agosto de 1107; os outros dados cronológicos aplicam-se ao ano de 1107. Cf. WISCHERMANN, Else Maria - Marcigny-sur-Loire. München: Fink, 1986, p. 409, que cita um estudo de H. Diener datado de 1959 no qual se atribui ao documento (Cluny, doc. 3862) a data crítica entre 22 de fevereiro e 13 de agosto de 1107.

${ }^{54}$ BISHKO, Charles Julian - op. cit., pp. 173-174. 
almas $^{55}$. Nele se refere a doação dos dízimos da produção agropecuária das suas possessões na Terra de Sanabria (Zamora) e de quatro igrejas em território leonêscastelhano. Por agora, resta-me dizer que a sua elaboração pelo notário régio Pelayo Erígez e a presença, entre o elevado número de quarenta e três confirmantes, de três bispos, três abades, três priores, um conde e três tenentes de terra, todos eles leoneses, e de próceres portugueses que se encontram fora dos seus senhorios em pleno inverno, contribuíram para a solenidade do ato.

\subsubsection{Um documento inédito particularmente esclarecedor}

Duas semanas antes, a 16 de janeiro de 1105, o conde D. Raimundo fez uma doação ao Mosteiro de São João de Poio, que se situa junto a Pontevedra. Desta doação tive conhecimento parcelar pelas obras de Prudêncio de Sandoval e de António Yepes, mas sem referência ao paradeiro do documento ${ }^{56}$. Seria necessário consultar a obra monumental de Antonio López Ferreiro para obter a vaga referência que estava no Archivo Histórico Nacional ${ }^{57}$. Por sua vez, Xosé Filgueira Valverde refere a existência de duas cópias do documento ${ }^{58}$. Ainda que sem precisar a localização daquele que se encontra no Arquivo Nacional de Espanha, informa que é uma cópia de letra do século XVI. Sem outros elementos percorri a documentação que se encontra online no Portal de Archivos Españoles (PARES) e, milagre da tecnologia, encontrei o documento

\footnotetext{
55 Documento de 30 de Janeiro de 1105, publicado por BISHKO, Charles Julian - "Count Henrique of Portugal, Cluny and the antecedents of the «Pacto Sucessório»". in Revista Portuguesa de História. 13 (1971), pp. 155-188.

${ }^{56}$ SANDOVAL, Prudêncio de - Antigüedades de Túy. Braga, 1610, f. 109r-v e Historia de los reyes de Castilla y de León. Pamplona, 1634, f. 95r-v. YEPES, Antonio de, A, Crónica General de la Orden de San Benito. Estudio preliminar y edición por Fr. Justo Pérez de Urbel. Madrid: Biblioteca de Autores Españoles, 1959-1960, n. 43, t. II, pág. 305.

57 LÓPEZ FERREIRO, Antonio - História de la Santa A. M. Iglesia de Santiago de Compostela. Santiago: Imp. y Enc. del Seminario Conciliar Central, 1900, t. III, p. 288, nota 2: «Documentos procedentes de San Juan de Poyo en el Archivo Histórico Nacional. - Yepes, Corónica..., t. V, al año 942, f. 61».

58 FILGUEIRA VALVERDE, Xosé - Tiempo y gozo eterno en la narrativa medieval: la cantiga CIII. Vigo: Edicións Xerais de Galicia, 1936, p. 110: «en 16 de enero de 1105 confirma com el título de 'maiordomus super mensam' la donación de coto hecha por los Condes al monasterio de Poyo» e, pela nota 279, ficamos a saber da existência de uma cópia do documento no «Archivo Arzobispal de Santiago, «Docs. Varios», t. I, ff. 19 a 47», para além da outra em «Docs. Del Monasterio de San Juan de Poyo. Inéditos. Copias de letra del s. XVI».
} 
inédito, de que obtive impressão sem sair de casa $^{59}$. Mas o vello profesor dá ainda a informação da sua existência também no Archivo Arzobispal de Santiago. Comecei por contactar o Archivo Histórico Diocesano de Santiago de Compostela, tendo o Sr. Damián Porto Rico informado que parte dos documentos do antigo archivo arcebispal estão atualmente no archivo catedralicio. Contactado o Archivo da Catedral de Santiago, foi possível, pelos bons serviços do Doutor Xosé Sanchez, identificar a cota atual do documento e uma deslocação do Porto a Santiago levou-me ao encontro certeiro da segunda cópia do inédito documento ${ }^{60}$. Recordo que Bernard Reilly o tinha dado como perdido ${ }^{61}$. Tive ainda o cuidado de verificar que não se encontra na recolha dos documentos da Galiza de D. Urraca, nem é referido na monografia da rainha ${ }^{62}$. Creio que tanto o documento do Archivo da Catedral de Santiago como o do Archivo Histórico Nacional são segundas cópias de uma transcrição do original, realizada em 29 de Janeiro de 1301 pelo notário de Compostela Laurentius Petri. A cópia do arquivo da catedral é figurada e, seguramente, a mais fiel ao original perdido, enquanto a cópia existente no arquivo nacional revela múltiplas intervenções modernas. Por esse motivo apresento no Anexo II a transcrição paleográfica da primeira, sinalizando contudo as variantes da segunda, dado que não me parece que esta tenha sido obtida diretamente a partir daquela ${ }^{63}$.

Ficamos deste modo a conhecer a cartula testamenti que o conde D. Raimundo, acompanhado da sua mulher D. Urraca e da filha Sancha, fizeram por sufrágio das suas almas ao mosteiro beneditino de São João do Poio. Nela se refere um importante

${ }^{59}$ ARCHIVO HISTÓRICO NACIONAL: CLERO-SECULAR/REGULAR, L.10319, «Libro único de el merino de el coto y su jurisdicción» do «Monasterio de San Xoán de Poio», f. 118 na numeração antiga e 126 na numeração nova.

${ }^{60}$ NOVÁS PÉREZ, Maria Elena - Catálogo de la Colección de Tomos de Varia (primeira serie) del Archivo-Biblioteca de la Catedral de Santiago de Compostela. Santiago de Compostela, 2006, pp. 13-14, sig.: IG 703/4 (fols. 19-41 del vol.) post. 1560 (sine loco): «Tralado de privilégios del monasterio de San Juan de Poyo de la ordem beneditina realizado por los notários Fernando de Rosende y Diego Suárez de Pazo». Inclui a doação de Raimundo de Borgonha nos ff. 39r-40r do volume.

${ }^{61}$ REILLY, Bernard F. - The Kingdom of León-Castilha under King Alfonso VI, 1065-1109. Princeton, Princeton University Press, 1988, p. 320, nota 76.

${ }^{62}$ RECUERO ASTRAY, Manuel (dir.) - Documentos medievales del reino de Galicia: Doña Urraca (1095-1126). Santiago de Compostela: Xunta de Galicia, 2002, e PALLARES, Maria del Carmen; PORTELA, Ermelindo - La reina Urraca. San Sebastián: Editorial Nerea, 2006, respetivamente.

$63 \mathrm{O}$ documento aqui transcrito, de forma a tornar mais acessível o conjunto dos passos dados para resolver os problemas suscitados pelo estudo do "pacto sucessório», foi, posteriormente à redação deste artigo, publicado em ESTEFÂNIO, Abel - "Um documento significativo para a história da Galiza", in Annuarium Sancti Iacobi, Archivo-Biblioteca de la Catedral de Santiago, no 2 (2013), pp. 17-30.

Medievalista online № 16 I Julho - De ze mbro 2014 (C) IEM - Instituto de Estudos Me dievais 19 www2.fc sh.unl.pt/ ie m/me die va lista 
património constituído por igrejas, herdades, salinas e a ilha de Tambo. Era preciso uma motivação forte para se reunirem, em pleno inverno, quarenta e quatro confirmantes, entre os quais três bispos, onze abades, dois condes, seis juízes e outras personalidades religiosas e civis com cargos na gestão do palácio e na administração do território da Galiza. Naturalmente, muitos outros homens e mulheres participaram no evento e asseguraram a sua logística, dos quais o diploma não nos informou. O documento também não nos elucida da razão da data escolhida, mas seria tão óbvia para todos os presentes na cerimónia que não precisava de ser registada na escritura e que, de alguma forma, o evento não podia ser adiado para o tempo mais clemente da primavera. D. Urraca estava no oitavo mês da gravidez de Afonso Raimundes que, como se sabe, viria a nascer perto do mosteiro, em Caldas de Reyes ${ }^{64}$. Não posso deixar de ligar a concessão deste privilégio ao nascimento do filho, como sendo a expressão de um voto para um parto bem-sucedido. A única filha que tinham, de que este documento é a primeira notícia que temos, devia ter então cerca de $10 \operatorname{anos}^{65}$. O conde D. Raimundo devia ansiar pelo nascimento de um filho varão. Creio ser essa a razão da invocação, na robora, de uma graça celeste ${ }^{66}$. Mas o acontecimento não se esgotaria na componente religiosa. Ficaram também selados importantes compromissos políticos, conforme se viria a manifestar mais tarde num processo liderado pelo conde Pedro Froilaz de Trava e pelo prelado compostelano D. Diogo Gelmires (as duas mais destacadas personagens que confirmaram a doação ao mosteiro de Poio), que culminou com a coroação do infante Afonso Raimundes como rei da Galiza no dia 17 de setembro de 1111, em Santiago de Compostela.

Devo esclarecer que o meu interesse pelo documento do conde D. Raimundo resulta da sua semelhança formal com o documento do conde D. Henrique, da aproximação das datas entre os dois documentos e dos locais onde foram produzidos, que, como notou

${ }^{64}$ Cfr. SANDOVAL, Prudêncio de - Historia de los reyes de Castilla y de Leon. Madrid: Benito Cano, 1792, p. 320: «Y el Arzobispo Don Rodrigo en el lib. 6 cap. 34 dice, en estos dias criaba en Galicia el Conde Don Pedro de Trava al Infante Don Alonso, hijo pequeño del Conde Don Ramon y de Doña Urraca, donde habia nacido en un lugar que llamaban Caldas de Rey, cerca del Monasterio de San Juan del Poyo y de Pontevedra, y en la costa del mar Océano».

${ }^{65}$ A filha Sancha teria nascido entre 1094 e 1095, cfr. AMARAL, Luís Carlos; BARROCA, Mário Jorge - op. cit., p. 50.

${ }^{66}$ Conf. Anexo II: «Ego Comes Raimundus celestis gratia conpuctus in hunc testamentum meo iussu factum manu mea confirmo».

Medievalista online № 16। Julho - De ze mbro 2014 (C) $\mathbb{E M}$ - Instituto de Estudos Me dieva is 20 www2.fc sh.unl.pt/ ie m/me die va lista 
Bernard Reilly, parecem inferidos no texto do pacto ${ }^{67}$. Da análise sistemática dos confirmantes de ambos os documentos, feita no sentido de formular uma interpretação credível do seu significado político, constato que nenhum dos confirmantes de um dos documentos confirma o outro. Todavia, não creio que daí se possa deduzir a existência de um antagonismo entre os condes borgonheses, como inferiu Charles Bishko. Talvez a doação do conde D. Henrique possa estar relacionada com o nascimento de uma das suas filhas, ou mesmo de um filho que não tenha sobrevivido, pois D. Afonso Henriques não deve ter nascido antes de $1106^{68}$. Seja como for, uma hipotética conspiração do conde D. Henrique contra D. Raimundo, como sustentou Bishko, seria extemporânea, sabendo-se que a filha legítima de Afonso VI estava prestes para dar à luz. Não creio, portanto, que o pacto tenha por base uma resposta a um desafio prévio de Henrique para a posse de Leão e Castela.

\subsection{A conjunção dos acontecimentos entre 1105 e 1107}

Ora, o nascimento de Afonso Raimundes, a 1 de março de 1105, veio estabelecer uma alternativa à sucessão do infante Sancho e a possibilidade, muito real, de uma regência dominada por Raimundo em nome do neto legítimo de Afonso VI. Dado a importância que se dava ao nascimento de um herdeiro masculino, o nascimento do futuro rei Afonso VII deve ter tornado as relações mais tensas entre Raimundo e Afonso VI e ajudado a precipitar os acontecimentos. Mas a reação pode não ter sido imediata. Algum tempo haveria de passar antes de ser claro que o recém-nascido iria sobreviver, dado que se estima que a taxa de mortalidade no primeiro ano de vida era da ordem de um em cada quatro nascimentos ${ }^{69}$.

\footnotetext{
${ }^{67}$ REILLY, Bernard F. - The Kingdom of León-Castilha under King Alfonso VI, 1065-1109. Princeton: Princeton University Press, 1988, p. 252: «The proper inference is that Raymond will likely be far away in Galicia and that Henry will be in León and in a position to seize the initiative».

${ }^{68}$ ESTEFÂNIO, Abel - "A data de nascimento de Afonso I". Medievalista [Em linha]. No 8 (Julho de 2010). [Consultado 13.09.2013]. Disponível em: http://www2.fcsh.unl.pt/iem/medievalista/MEDIEVALISTA8lestefanio8002.html

${ }^{69}$ Cfr. REILLY, Bernard F. - The Kingdom of León-Castilha under King Alfonso VI, p. 338.
} 
É por isso que ainda vemos num documento de Afonso VI de 31 de março de 1105, o infante Sancho a confirmar após o conde D. Raimundo ${ }^{70}$. Mas, a partir de setembro de 1105, o filho de Afonso VI começa a figurar nos diplomas imediatamente depois da rainha sua mãe e antes dos condes borgonheses; sinal inequívoco de sua ascensão, ao menos de facto, à categoria de herdeiro ${ }^{71}$. O infante Sancho volta a aparecer em 19 de março de 1106, numa concessão do seu pai à igreja de Oviedo, feita em Sahagún ${ }^{72}$. É novamente em Sahagún que confirma um documento particular a 18 de janeiro de $1107^{73}$. Num documento da Catedral de Astorga, datado de 14 de abril de 1107, o rei Afonso VI, referindo expressamente estar acompanhado de sua mulher Isabel e do filho de ambos, Sancho, concede uns foros aos povoadores de Riba de Tera e Valverde ${ }^{74}$. Confirmam o documento, logo a seguir, o arcebispo de Toledo D. Bernardo, e os condes Henrique e Raimundo. Um documento particular de São Salvador de Oña, datado do dia 23 do mesmo mês, revela que Sancho já tinha recebido de seu pai o comando oficial militar da fortaleza chave de Medinaceli, que Afonso VI tinha conquistado em $1104^{75}$. A 8 de maio de 1107, Afonso VI concede um diploma à catedral de Toledo datado do castelo de Monzón. A fórmula de datação revela ter sido executado pouco depois de uma cúria em Leão ${ }^{76}$. Como vinha acontecendo, Sancho confirma o diploma imediatamente após a sua mãe. A confirmação dos dois condes borgonheses e das suas mulheres dão-nos indicação que também devem ter participado nessa reunião. Seis dias depois, Afonso VI concede ao bispo de Santiago o privilégio de cunhagem de moeda. Os dois condes borgonheses e as suas mulheres estão presentes a confirmar este documento em que, de uma forma explícita, aparece a nomeação oficial de Sancho

\footnotetext{
${ }^{70}$ GAMBRA, Andrès - op. cit., t. 2, doc. 182. O conde D. Henrique, que habitualmente confirma após o conde D. Raimundo, está ausente neste documento.

${ }^{71}$ Ibid., doc. 184 (1105, setembro, 22).

${ }^{72}$ Idem, doc. 185.

${ }^{73}$ HERRERO DE LA FUENTE, Marta - Coleccion Diplomática del Monasterio de Sahagún (857-1230). Vol. III (1073-1109). León: Centro de Estudios e Investigacion San Isidoro, 1988, doc. 1150.

${ }^{74}$ SALAZAR Y ACHA, Jaime de - "De nuevo sobre la mora Zaida", Hidalguia. No 321 (2007), p. 241, citando Gregoria CAVERO DOMÍNGUEZ e Encarnación MARTIN-LÓPEZ - Colección Documental de la Catedral de Astorga. I (646-1126) e II (1126-1299). Léon: Centro de Estudios e Investigacion San Isidoro, 1999, I, 534, p. 397: «cum uxore mea Elisabet et filio nostro Sancio».

${ }^{75}$ Documento original de 23 de Abril de 1107. AHN, Clero, Carpeta 272, no 9; publicado por ALAMO, Juan del (ed.) - Colección diplomática de San Salvador de Oña. Madrid: CSIC, 1950, tomo I, doc. $\mathrm{n}^{\circ}$ 128, pp. 163-164,: «regnante rege Adefonso in Toleto et in Leione et in omni regno Yspanie. Santius filius eius in Medina».

${ }^{76}$ GAMBRA, Andrès - op. cit., t. 2, doc. 188: «post celebratum concilium apud Legionem».
} 
como herdeiro do trono ${ }^{77}$. Podemos admitir que o recente concílio teve por principal finalidade o reconhecimento de Sancho como o sucessor oficialmente designado do rei Afonso VI. O infante deve ter atingido a maioridade, que naquela época era aos 14 anos. É difícil estabelecer uma relação de causa e efeito destes acontecimentos com a realização do pacto. A perspetiva de que a coroa fugisse ao «Partido Borgonhês» inquietava a abadia de Cluny. Era aí que, nas palavras do grande historiador Alexandre Herculano, «um velho monge influía então nos negócios mais graves da Europa» ${ }^{78}$. As más relações de Afonso VI com o abade Hugo de Semur, identificadas recentemente por Júlia Montenegro, ajudam-nos a entender melhor a intervenção do abade em relação à crise sucessória, consubstanciada no «pacto sucessório» ${ }^{79}$.

Os termos que o pacto propõe para o conluio dos condes enquadram-se no tipo de autoridade e de governo da Borgonha, caracteristicamente feudais. Faz parte da sua proposta de acordo que os condes deviam tomar Toledo, cidade onde Afonso VI fora retirar o seu título imperial ${ }^{80}$. $\mathrm{O}$ abade Hugo pretendia dessa forma alavancar os poderes de que os condes haviam sido investidos em resultado dos seus casamentos com as filhas de Afonso VI, ponderados apenas pelo caráter diferenciador decorrente de uma das infantas ser legítima e a outra não ${ }^{81}$. Se o conde D. Raimundo via confirmado o seu

${ }^{77}$ Ibid., doc. 189, de 14 de maio de 1107: «Sancius puer filius regis regnum electus patrifactum conf.». É possível que esta porção de texto tenha sido a fonte utilizada por Rodrigo Jiménez de Rada, no De Rebus Hispaniae, para informar que, em 1108, quando participa na Batalha de Uclés, Sancho era ainda criança. Jiménez de Rada usa parvulo como sinónimo de puer, que entendeu como criança, mas segundo o dicionário de Niermeyer (NIERMEYER, J. F. - Mediae latinitatis lexicon minus. Leiden: Brill, 2002) puer pode também significar jovem príncipe, o que me parece ser mais adequado. Por essa razão sigo os autores que colocam o nascimento provável de Sancho por volta de 1103. Não posso deixar de fazer um paralelo com o conde D. Henrique, que surge pela primeira vez num documento de 1079 em que aparece mencionado entre os confirmantes. Três anos mais tarde, numa carta datada de 1082, Henrique da Borgonha, é tratado como puer. O tratamento repete-se num outro diploma datado de 1083 . Também não se conhece o ano exato do nascimento do futuro conde portucalense, mas supomos que terá nascido por volta de 1069, pelo que teria então 13 ou 14 anos (AMARAL, Luís Carlos; BARROCA, Mário Jorge - op. cit., p. 37).

${ }^{78}$ HERCULANO, Alexandre - História de Portugal. Pref. e notas críticas de José Mattoso. t. I. Lisboa: Bertrand, 1989, p. 282.

${ }^{79}$ A Professora Júlia Montenegro veicula a tese de o diploma de confirmação solene do censo duplicado, datado do tempo pascal de 1090, ser um falso, o que lhe permite propor que as relações de Afonso VI com Cluny «debieron de quedar seriamente deterioradas a partir de 1080 y heridas de muerte diez anos más tarde» e conclui que «Así se entende mejor la actitud de Cluny en relación com la crisis sucessória que tantas aflicciones provocó a Alfonso VI y a sus reinos» (MONTENEGRO, Julia - "La alianza de Alfonso VI com Cluny y la abolición del rito mozárabe en los reinos de León y Castilla: una nueva valoración”. in Iacobus: revista de estúdios jacobeos y mediavales. Sahagún, no 25-26 (2009), pp. 47-62). ${ }^{80}$ «Imperator Toletanus». Vd. GAMBRA, Andrès - op. cit., t. 1, pp. 702-705.

${ }^{81} \mathrm{Na}$ doação que faz da igreja de Santa Maria Madalena de Sahagún, em 1 de maio de 1106, o conde Raimundo e a sua mulher fazem uma exibição deliberada dos seus direitos soberanos à sucessão

Medievalista online № 16। Julho - De ze mbro 2014 ( $\mathbb{E M}$ - Instituto de Estudos Me dieva is 23 www2.fc sh.unl.pt/ ie m/me die va lista 
direito de suceder a Afonso VI, o conde D. Henrique assegurava uma posição política excecional. O conde D. Raimundo chega mesmo a admitir a possibilidade de dar a Galiza ao conde D. Henrique, caso não lhe pudesse dar Toledo, o que não era de todo descabido, face à ameaça almorávide. Se o conde D. Henrique juntasse a Galiza ao Condado Portucalense, ficaria na posse de todo o território administrado pelo conde D. Raimundo antes da sua chegada à Península Ibérica. Mas a trama dos acontecimentos não seguiria nesse sentido. Os recentes biógrafos de D. Teresa salientam o carácter provisório da redação, tanto do "pacto sucessório" realizado pelos dois condes borgonheses, como a do "pacto de amizade" realizado mais tarde pelas duas filhas de Afonso VI, suas mulheres, como se os intervenientes tivessem consciência da condição efémera dos convénios estabelecidos ${ }^{82}$.

\subsection{As profundas alterações no cenário político que lhe sucederam}

No que respeita ao "pacto sucessório", que é o que agora nos interessa, uma sucessão de mortes tornou-o rapidamente obsoleto. Em primeiro lugar, a já referida morte de D. Raimundo, em Grajal, no dia 20 de setembro de 1107. Inevitavelmente, a morte do conde envolveu grandes alterações no equilíbrio político real do reino, e estas mudanças tiveram que ser abordadas formalmente. Entre outubro e dezembro de 1107 realizou-se uma assembleia magna em Leão ${ }^{83}$. O velho rei leonês estipula que o filho Afonso

(HERRERO DE LA FUENTE, Marta - op. cit., doc. 1142: «comes Raimundus habens principatum apud Hispanie» e « regalibus orta natalibus ego Urracha». BISHKO, Charles Julian - op. cit., p. 185 e nota 85: «Note also that elsewhere in this document the Condes refer to 'regalem morem' and 'reges nostri antecessores', while Gelmirez' eschatocol describes the text as 'testamentum regale'»). Novamente, num pergaminho de 17 de março 1107, Raimundo proclama-se um homem com autoridade absoluta sobre a Galiza, ainda que esse poder lhe advenha do seu sogro Afonso VI (LUCAS ÁLVAREZ, Manuel - $L a$ documentación del Tumbo A. Estudio y edición. León: Centro de estudios e investigación San Isidoro, 1997, doc. 76: «...Ego comes domnus Raimundus, totius Gallecie imperator seu Adefonsi Tolletane principis gener»). Segundo Rodrigo Ximénez de Rada (De Rebus Hispaniae, cit. de MARTINS, Armando - "Cluny e a formação de Portugal", in A Idade Média Portugusesa e o Brasil: reminiscências, transformações, ressignificações. Porto Alegre: Vidráguas, 2011, p. 91, nota 61) D. Afonso VI teria expulsado da corte o seu genro D. Raimundo, por suspeita de reivindicação indevida do poder. Por seu lado, o conde Henrique, na doação da herdade de S. Romão (concelho de Seia) em 1 de agosto de 1106 apresenta-se «Ego comes Henrricus Portugalensium patrie princeps» (AZEVEDO, Rui de (ed.) - Documentos Medievais Portugueses, Documentos Régios. Lisboa: Academia Portuguesa da História, 1958, I, doc. 10).

${ }^{82}$ AMARAL, Luís Carlos; BARROCA, Mário Jorge - op. cit., pp. 183-184.

${ }^{83}$ GAMBRA, Andrès - op. cit., t. 1, p. 549. 
Raimundes ficaria com a Galiza se a sua mãe voltasse a casar. $\mathrm{O}$ ato foi presenciado pelo arcebispo Guido de Vienne, que em 1119 se tornaria no Papa Calixto II. É provável que ele tenha sido convocado para ajudar a proteger os interesses do seu sobrinho ${ }^{84}$. É possível que na mesma ocasião ou no início do ano seguinte, o rei tenha colocado nas mãos do jovem infante Sancho o governo de Toledo, pois é a ele que o rei confia o comando da expedição enviada em socorro de Úcles ${ }^{85}$. No decurso da batalha travada a 29 de maio de 1108 o infante encontra a morte. A reação de Afonso VI ao funesto evento não deve ter sido muito diferente das palavras que o arcebispo de Toledo Don Rodrigo Jiménez de Rada colocou na boca do rei: «Dónde está mi hijo, la alegría de mi vida, el consuelo de mi vejez, mi único heredero?». O rei autoritário que se assumiu ao longo da vida como representante de Deus na luta contra os infiéis, encontrava-se agora velho e acompanhado da doença que o havia de conduzir à morte ${ }^{86}$.

Em 22 de fevereiro de 1109, a infanta Urraca doa ao abade Hugo o mosteiro galego de São Vicente de Pombeiro, seguindo o conselho do seu pai ${ }^{87}$. Depois de gorado o seu plano de sucessão hostil a Cluny, o rei soçobrava e procurava agora uma reaproximação de forma a obter o reconhecimento e aceitação da infanta como sua sucessora e herdeira. O Abade Hugo deve ter ficado satisfeito com o inesperado volte-face que acabaria por colocar no trono a sua sobrinha-neta.

\footnotetext{
${ }^{84}$ É a partir da Historia Compostelana (FLÓREZ, Enrique - España Sagrada. Madrid: M. F. Rodríguez, 1765, vol. 20, pp. 95-96) que sabemos que o arcebispo Guido de Vienne (na França), irmão de Raimundo e futuro Papa Calisto II, esteve presente. O velho rei concede ao infante Afonso Raimundez o direito de herdar o governo da província da Galiza, se a sua mãe voltar a casar: «nepoti meo, proculdubio famulatures exhibeo, et totam ei Gallaetiam concedo, si ejus mater Urraca virum ducere voluerit».

${ }^{85}$ FALQUE REY, Emma (ed.) - Historia Compostelana. Madrid: Ediciones AKAL, 1994, p. 125: «el hijo del rey, Sancho, a cuya custodia según ordem de su padre estaba confiado el domínio de Toledo».

${ }^{86}$ A Crónica del obispo don Pelayo (cit. de MONTENEGRO, Julia - "La crisis sucessória...", op. cit., 2010, p. 388, nota 45) refere que o rei esteve enfermo dezanove meses antes de morrer: «Cum iam tempus immineret mortis eius decidit in lecto et parmansit in infirmitate annum unum integrum et mensibus septem». UBIETO ARTETA, Antonio, (ed.), Crónicas Anónimas de Sahagún. Zaragoza: Anubar Ediciones, 1987, p. 25: «Ca como el de la mui noble memoria rei don Alfonso feçiese sesenta y dos annos de su hedad e ya mucho obiese estado enfermo en la muy noble cibdad que él había ganado del poderio de los islmaelitas e infieles, conviene a saber, de Toledo, en el quarenta y quatro annos de su reino pagó la debda de la natura mortal».

${ }^{87}$ BISHKO, Charles Julian - "The Cluniac Priories of Galicia and Portugal: Their Acquisition and Administration (1075-ca.1230)". in Studia Monastica. 7 (1965), p. 306, liga esta doação «to the imminent accession of Alfonso VI's daughter, the Infanta Urraca».
} 
Quem veria frustradas as suas espectativas seria o conde D. Henrique, que perdia as vantagens prometidas no pacto, agora caduco. O Autor da Primeira crónica anónima de Sahagún, relata o sucedido ${ }^{88}$ :

«poucos dias antes que o rei [D. Afonso VI] falecesse, não sei porquê (sem dúvida por desconhecer o pacto e as aspirações que ele tinha gerado na mente do conde D. Henrique), intervindo discórdia e sanha, [D. Henrique] afastou-se com a ira do rei».

O Professor José Mattoso considera que esta notícia dá a informação da rutura do vínculo de fidelidade de Henrique para com Afonso VI ${ }^{89}$. E continua o Autor Anónimo:

«E por esta razão, quando o rei estava a morrer e dispunha sobre a sucessão do reino, este conde não estava presente, pois sendo do reino afastado, atravessou os montes Pireneus para obter ajuda dos franceses, com os quais, fortalecido e esforçado, esperava tomar o reino de Espanha pela força».

Apesar da opinião em contrário de Henrique Barrilaro Ruas, o conde D. Henrique deve ter colocado na «agenda» de Afonso VI o problema da sucessão ${ }^{90}$. Percebe-se no texto transcrito a referência a França por oposição aos interesses da aristocracia hispânica. A viagem do conde D. Henrique, cujo destino talvez fosse a abadia de Cluny, deve ter sido iniciada depois de 22 de maio de $1109^{91}$. Se, de facto, chegou a atravessar os Pirenéus, já não se encontrou com o abade Hugo, pois este tinha falecido a 28 de abril desse ano. Também não mais voltaria a ver o seu sogro, que morreu em 1 de julho de 1109 . No dia seguinte ao enterro do rei em Sahagún, a 22 de julho, D. Urraca emite em Leão o seu primeiro diploma como rainha ${ }^{92}$. Entre os confirmantes encontra-se o arcebispo de Toledo D. Bernardo de Sauvetat. É provável que, uma semana depois, o conde D.

${ }^{88}$ AMARAL, Luís Carlos; BARROCA, Mário Jorge - op. cit., p. 317.

${ }^{89}$ Mattoso, José - D. Afonso Henriques. Lisboa: Temas e Debates, 2007, p. 31.

${ }^{90}$ RUAS, Henrique Barrilaro - Se partio ayrado del rrei. Separata da Revista Portuguesa de História. Coimbra, tomo IV, 1955.

${ }^{91}$ HERRERO DE LA FUENTE, Marta (ed.) - Colección Diplomática del Monasterio de Sahagún, III, Leon: Centro de Estudios e Investigacion San Isidoro, 1988, doc. 1167.

92 RUIZ ALBI, Irene - La Reina Doña Urraca (1109-1126). Cancillería y colección diplomática. León: Centro de Estudios e Investigacion San Isidoro, 2003, doc. 1: «ego Urraka, Dei nutu totius Yspanie regina». 
Henrique, regressado recentemente da sua viagem, se tenha encontrado em Leão com D. Bernardo para a feitura do documento de doação do mosteiro de S. Mamede do Lorvão à Sé de Coimbra ${ }^{93}$. Com arrojo, sentencia que nem rei nem conde a poderiam anular ${ }^{94}$. Estribado no apoio do arcebispo cluniacense e primaz das Espanhas, que lhe conferia um reconhecimento notável da sua autoridade, não encobre as suas aspirações de independência. $\mathrm{O}$ conde $\mathrm{D}$. Henrique, que antes declarava que recebera a terra portugalense do rei, seu sogro, considera agora que a legitimidade do seu poder provém de Deus ${ }^{95}$. Segue para Viseu onde os nobres, o clero e os cavaleiros de Viseu confirmam o documento ${ }^{96}$. Daí, parte para Coimbra para a realização da cerimónia solene, in loco, sobre o altar da catedral ${ }^{97}$. Congrega agora no ato os nobres, o clero e os cavaleiros de Coimbra. Torna-se evidente o caráter extraordinário desta doação e o seu significado político. São os primeiros alvores, ainda incertos, da aurora na nacionalidade...

${ }^{93}$ RODRIGUES, Manuel Augusto; COSTA, Avelino de Jesus da; VELOSO, Maria Teresa Nobre (ed.) Livro Preto, cartulário da Sé de Coimbra, Coimbra: Arquivo da Universidade de Coimbra, 1999, doc. 59, de 29 de julho de 1109.

94 Ibidem: «Si autem quilibet rex aut comes, seu cujuscumque dignitatis et potentie homo, illud irrumpere temptaverit, ...».

95 Idem: «Ego, Henricus, Dei gratia comes et totjus Portugalis dominus».

96 Idem: «Hec sunt nomina confirmantium qui viderunt et audierunt hanc cartam confirmatam in Viseo...». Talvez a confirmação em Viseu resulte de uma alteração do plano inicial de D. Bernardo se deslocar a Coimbra. O arcebispo de Toledo retornaria para Leão onde, a 10 de Setembro de 1109, confirma o documento no qual D. Urraca renova os foros de concelho de Leão que seu pai havia outorgado (RUIZ ALBI, Irene - La Reina Doña Urraca, op. cit., doc. 2).

97 AZEVEDO, Rui de (ed.) - Documentos Medievais Portugueses, Documentos Régios, doc. 15. Este documento da cerimónia de Coimbra deve ser uma cópia do documento original, que teve confirmação em Viseu. Não creio o inverso, ou seja, da confirmação posterior em Viseu da doação realizada em Coimbra. É duvidosa a informação dos Annales Portucalenses Veteres que sustentava esse percurso, de o conde D. Henrique ter comandado um exército para recuperar o castelo de Sintra, cujos habitantes se teriam revoltado quando souberam do falecimento de Afonso VI, (conf. MATTOSO, José - D. Afonso Henriques. Lisboa: Temas e Debates, 2007, p. 32, nota 1). 


\section{Anexo I}

[1105, 1107] - Carta enviada a D. Hugo, abade de Cluny, com o pacto de amizade estabelecido entre os condes D. Raimundo e D. Henrique, relativo à sucessão do sogro deles, o rei Afonso VI, escrito e jurado na presença do camareiro D. Dalmácio Geret.

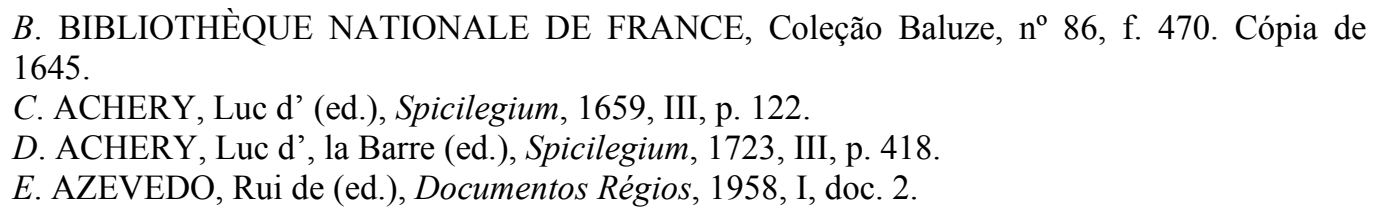

Domino atque Reverentissimo Cluniacensi Abbati Hugoni, omnique beati Petri Congregationi, R[aimundus] Comes eiusque filius [Alfonsus Raimundi], et H[enricus] Comes eius ${ }^{98}$ familiaris, cum dilectione salutem in Christo. Sciatis, Karissime ${ }^{99}$ Pater, quòd postquàm vestrum vidimus legatum pro Dei omnipotentis atque Beati Petri Apostoli timore vestræque dignitatis reuerentia quod nobis mandastis in manu Domni Dalmatii Geret fecimus.

In nomine Patris et Filii et Spiritus Sancti. Pignus integræ dilectionis, quo coniuncti ${ }^{100}$ sunt in amore R[aimundus] Comes, Comésque $\mathrm{H}$ [enricus], et hoc iuramento.

Ego quidem $\mathrm{H}$ [enricus] absque ulla diuortii falsitate tibi Comiti $\mathrm{R}$ [aimundo] membrorum tuorum sanitatem, tuæque vitæ integram dilectionem, tuique carceris inuitam mihi occursionem iuro: Iuro etiam quod post obitum Regis IL[defonsi] tibi omni modo contra omnem hominem atque mulierem hanc totam terram Regis $\mathrm{Al}$ [fonsi] defendere fideliter ut Domino singulari atque occurrere ${ }^{101}$ præparatus occurram. Iuro etiam si thesaurum Toleti prius te habuero, duas partes tibi dabo et tertiam mihi retinebo, amen.

Et ego Comes $\mathrm{R}$ [aimundus] tibi Comiti $\mathrm{H}$ [enrico] tuorum membrorum sanitatem, tuæque vitæ integram dilectionem, tuique carceris inuitam mihi occursionem iuro. Iuro etiam quod post mortem Regis IL[defonsi] me tibi daturum Toletum terramque totam subiacentem ei, totamque terram, quam obtines modo a me concessam, habeas tali pacto; vt sis inde meus homo, et de me eam habeas Domino; et postquam illas tibi dedero, dimittas mihi omnes terras de Leon et de Castella; Et si aliquis mihi vel tibi obsistere voluerit, et iniuriam nobis fecerit, guerram simul in eum vel vnusquisque per se ineamus, vsquequo terram illam mihi vel tibi pacificè dimittat, et postea tibi eam præbeam. Iuro etiam si thesaurum Toleti prius te habuero, tertiam partem tibi dabo et duas remanentes mihi seruabo.

Fiduciam quam Comes R[aimundus] fecit in manum Domini Dalmatii Geret:

Si Ego Comes R[aimundus] nom possum tibi Comiti $\mathrm{H}$ [enrico] dare Toletum ut promisi, dabo tibi Gallæciam, tali pacto ut tu adiuues mihi adquirere totam terram de Leon et de Castella, et postquam inde Dominus pacifice fuero, dabo tibi Gallæciam, ut postquam eam tibi dedero, dimittas mihi terras de Leon et de Castella. Igitur Deo iubente, sic quoque Sancta Dei Ecclesia piis orationibus interueniat, amen.

\footnotetext{
1 eius] $E$ omite.

${ }^{2}$ karissime] $C D E$ carissimo.

${ }^{3}$ conjuncti] $D$ conjucti. $E$ conjucti (sic).

${ }^{4}$ occurrere] $C D E$ adquirere.
} 


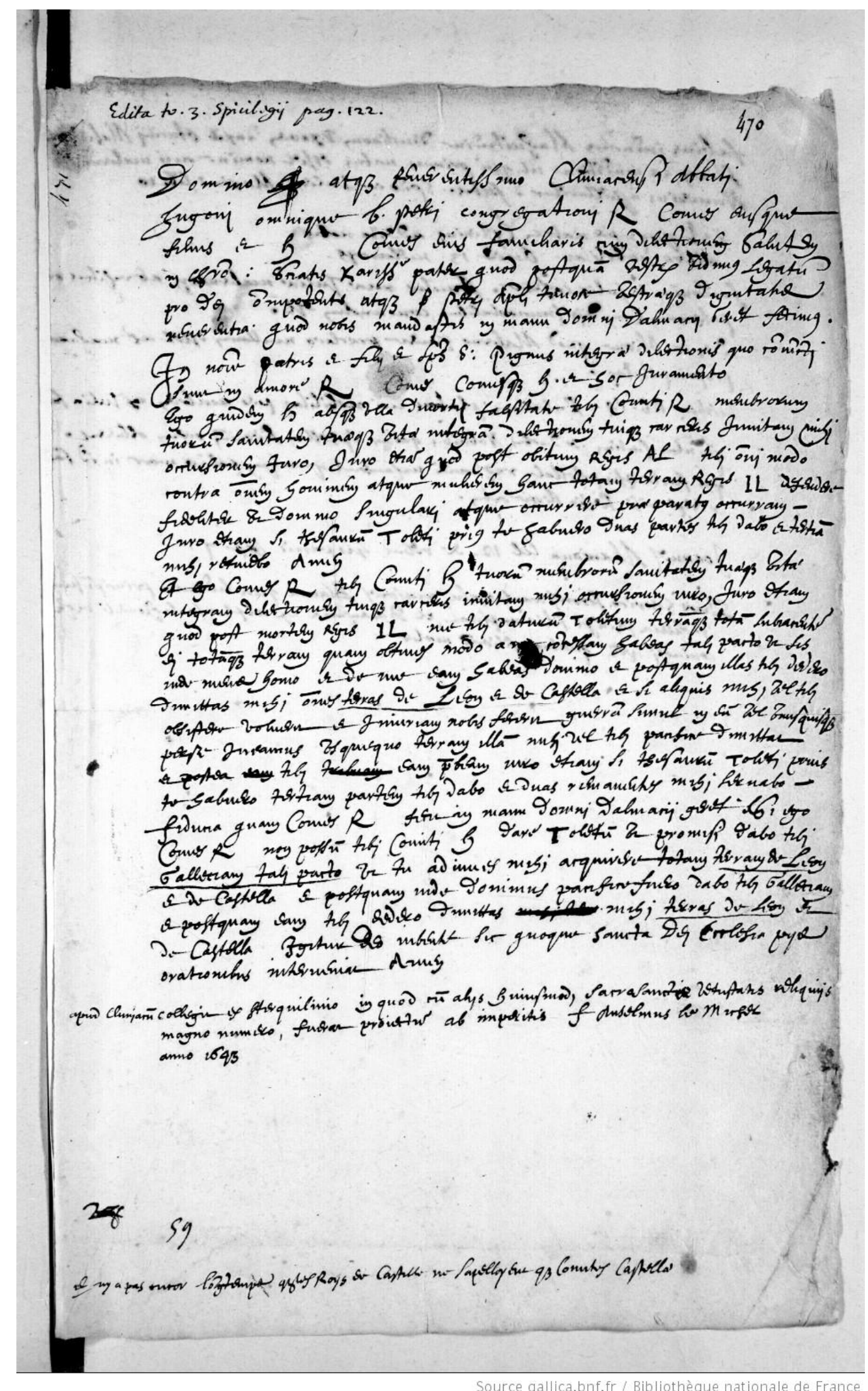

Manuscrito do "pacto sucessório", Recueil de Chartes de CLUNY, 
Proposta de aclaração do "pacto sucessório" à luz de novos dados • Abel Estefânio

Bibliothèque Nationale de France, Département des manuscrits, Coleção Baluze $n^{\circ} 86$, f. 470 . 


\section{Anexo II}

1105, Janeiro, 16 - O conde D. Raimundo e sua mulher Dona Urraca fazem um importante conjunto de doações ao Mosteiro de São João de Poio.

C. ARCHIVO DE LA CATEDRAL DE SANTIAGO DE COMPOSTELA, Tomo I de la Primera Serie de la Colección de Tomos de Varia (signatura: ACS, IG 703), ff. 39 e 40.

D. ARCHIVO HISTÓRICO NACIONAL: CLERO-SECULAR/REGULAR, L.10319, «Libro único de el merino de el coto y su jurisdicción» do «Monasterio de San Xoán de Poio», fólio 118 na numeração antiga e 126 na numeração nova.

Aludido em RECUERO ASTRAY (coord.) - Documentos Medievales del Reino de Galicia: Doña Urraca (1095-1126). Santiago de Compostela: Xunta de Galicia, 2002, doc. 41 de 1116.03.31: «Et sicuti uobis dedi medietatem una cum uiro meo, comite domno (Raimun)do in primis similiter do uobis modo aliam medietatem...».

Citado por PRUDÊNCIO DE SANDOVAL - Antigüedades de Túy, Braga, 1610, f. 109r-v e Historia de los reyes de Castilla y de León, Pamplona, 1634, f. 95r-v, ANTONIO DE YEPES Crónica General de la Orden de San Benito. Estudio preliminary y edición por Fr. Justo Pérez de Urbel. Madrid: Biblioteca de Autores Españoles, 1959-1960, n. 43, t. II, pág. 305, LÓPEZ FERREIRO, Antonio - História de la Santa A. M. Iglesia de Santiago de Compostela. Santiago: Imp. y Enc. del Seminario Conciliar Central, 1900, Tomo III, p. 288 e FILGUEIRA VALVERDE, Xosé - Tiempo y gozo eterno en la narrativa medieval: la cantiga CIII. Vigo: Edicións Xerais de Galicia, 1936, p. 110.

In nomine sancte et individue trinitatis Cristi. Sancti ${ }^{1}$ Joanis $^{2}$ Baptiste honore et aliorum sanctorum quorum reliquie hic continentur et quorum ecclesia est fundata loco predicto quod dicunt ${ }^{3}$ Poio territorio Salinense ripa maris inter monte Castroue et ribulum Lerice. Ego quidam comes Raimundus ${ }^{4}$, imperatoris Adefonsi ${ }^{5}$ gener et totius Gallecie ${ }^{6}$ dominus, una cum coniuge mea domna Urraca, eiusdem imperatoris filia, peccatorum mole $^{7}$ depressi, atque celestis ${ }^{8}$ misericordie compuncti concedimus huic ecclesie ${ }^{9}$ Sancti $^{-}$ Joannis Baptiste et Sancti Andrea apostoli, pro animarum nostrarum remedio, in cirsuitu ipsius ecclesie LXXX et IIII $^{\text {or10 }}$ passales ab integro sine aliqua dominatione omnium hominum et ex omnibus hominibus, atque hereditatibus qui sunt modo vel fuerint usque in finem in suo cauto quod est de Custodias usque ad Sanctum Petrum de Campaniola damus ex eis medietatem integram de hereditatibus vero id sunt, de Conbarro ${ }^{11}$ medietatem, de Curiales medietatem, de Ranecta ${ }^{12}$ medietatem, Sancte Marie ecclesia integra, de Raapazules ${ }^{13}$ medietatem, de Villares ${ }^{14}$ medietatem, de Casal de Aluito medietatem, de Rial medietatem, de Maurelles ${ }^{15}$ medietatem, de Pereira medietatem, de Bustello medietatem, Paradella ${ }^{16}$ integra, de Fenulucto ${ }^{17}$ medietatem, de Moreira medietatem, de Alariz medietatem, de Pagan medietatem, de Villarino ${ }^{18}$ medietatem, de altero Villarino ${ }^{19}$ medietatem, de Casales ${ }^{20}$ de Dona Goto medietatem et extra cautum in territorio Morraco ${ }^{21}$, Sancte Marie ecclesia integra de Beluco ${ }^{22}$, ecclesia Sancte Marine de Maurena integra, ecclesia Sancti Saluatoris de Poyo media, ec[c]lesia Sancti Petri de Campaniola media, ecclesia Sancte Marie de $\operatorname{Simes}^{23}$ media, ecclesia Sancti Petri de Tomeça $^{24}$ media, ecclesia Santi Petri de Cornaço ${ }^{25}$ media, insula de Thalauo ${ }^{26}$ integra, ecclesia Sancti Saluatoris de Cordeiro ${ }^{27}$ integra, salinas qui sunt in marina Sancti Laurentii, IIII ${ }^{\text {or28 }}$ salinas in corte de Elduara, VI ${ }^{\text {ex29 }}$ in corte Christofoli et in Gonelli ${ }^{30}$ una integra et altera media et corte de Mulieres ${ }^{31}$ integra cum omnibus suis vivaribus ${ }^{32}$ et caldaribus ${ }^{33}$ et aquis dulcibus ${ }^{34}$ ab integro. Sic damus et concedimus omnes istas hereditates atque homines huic sancte ecclesie, ut habeant eas omnes serui Dei confesores illius ecclesie absque ulsa omnium hominum dominatione, tam laicorum quam etiam aliorum hominum ${ }^{35}$, tam generationum nostrarum quam etiam et 
extraneorum, sed semper stent post partem ipsius monasterii et omnium hominum in ordine Sancti Benedicti Deo seruientium nunc et in perpetuum.

Facta Series testamenti sub die quod erit XVII kalendas ${ }^{36}$ februarii, era millessima centessima $\mathrm{XL}^{\mathrm{n}} \mathrm{III}^{37}$. Si aliquis homo hanc scripturam quam eligemus ${ }^{38}$ temptare vel $^{39}$ irrumpere voluerit, quis quis ille fuerit, participetur cum Juda traditore et maledicatur ${ }^{40} \mathrm{a}$ Deo omnipotenti et hunc nostrum factum psenam atque perfectam habeat stabilitatem in secula seculorum.

Ego Comes Raimundus celestis ${ }^{41}$ gratia conpuctus ${ }^{42}$ in hunc testamentum meo iussu factum manu mea confirmo. Domna Urraca illius uxoris confir. Inffanta ${ }^{43}$ domna Santia $^{44}$ illorum filia confir. Sub diuino auxilio Didacus Compostellane ecclesie episcopus confirmat. Adefonsus ${ }^{45}$ Tudensis ecclesie episcopus confirmat. Didacus Auriensis ${ }^{46}$ episcopus confirmat. Joanes ${ }^{47}$ Ranamirez qui tunc erat maiordomus illius comitis confir. Pelagius Gudesteis ${ }^{48}$ confir. Guncaldus ${ }^{49}$ Didas confir. Froila Menendiz confir. Froila Arias confir. Petrus infancti presbiter Carboniensis hic confir. Petrus

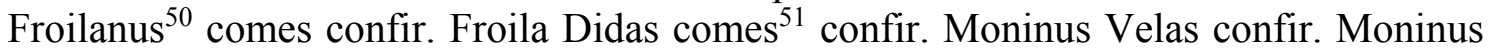
Pelagius $^{52}$ armiger comitis confir. Ero Armentaris ${ }^{53}$ maiordomus super mensam confir. Odiarius $^{54}$ Sancti Jacobi archidiaconus confir. Gudesindus canonice ${ }^{55}$ Sancti Jacobi abbas confir. Moninus Gudesteis ${ }^{56}$ maiordomus in Lopeira ${ }^{57}$ confir. Pelagius Gudesteis $^{58}$ iudex Sancti Jacobi confir. Petrus Danielis iudex apostolice aule confir. Menendus Guncadis ${ }^{59}$ iudex confir. Gundisindus abbas ${ }^{60}$ confir. Petrus capellanus illius infantis notarius confir. Fromaricus ipsius monasterii abbas qui testamentum hunc scripsit $^{61}$ confir. Petrus abbas Celenove confir. Petrus abbas de Antealtares confir. Leouigildus Sancti Martim abbas confir. Aldefonsus ${ }^{62}$ Sancti Laurentii abbas confir. Ordonius abbas de Morraco ${ }^{63}$ confir. Petrus abbas de Caldas confir. Gundesindus Liandris ${ }^{64}$ de Caldas iudex confir. Cresconio Citis ${ }^{65}$ iudex confirmat. Didacus abbas de Arcus confir. Nunius ${ }^{66}$ abbas Sancti Salvatoris de Lerez confir. Didagus iudex terra Tabeirolo confir. Nunius ${ }^{67}$ Pelas de Montes confirmat. Petrus Arias confirmat. Fernandus Arias confirmat. Fernandus Joannes confirmat. Ovecus Cresconis ${ }^{68}$ confirmat. Didacus Arias conf. Gudesteus ${ }^{69}$ Ferdinandi confirmat. Pelagius Ramiriz confirmat. Fernandus Ordunez ${ }^{70}$ confirmat. Aluiens Cengoibus ${ }^{71}$ confirmat (signum varia).

Variantes em $D: \mathrm{O}$ «e» final de algumas palavras foi substituído pelo ditongo «ae». ${ }^{1}$ Omite Sancti ${ }^{2}$ Joannis ${ }^{3}$ dicitur ${ }^{4}$ Raymundus ${ }^{5}$ Adephonsi ${ }^{6}$ Galeciae ${ }^{7}$ molte ${ }^{8}$ eclesiis ${ }^{9}$ Por esta e todas que se seguem eclessiae ${ }^{10} \mathrm{LXXX}$ et IIII ${ }^{\text {or }}$ ] octoginta quatrior ${ }^{11}$ Combarro ${ }^{12}$ Caneita ${ }^{13}$ Baarazules ${ }^{14}$ Vilares ${ }^{15}$ Maurelos ${ }^{16}$ Paradela ${ }^{17}$ Fenulicto ${ }^{18}$ Vilarino ${ }^{19}$ Vilarino ${ }^{20}$ Cassales ${ }^{21}$ Morrazo ${ }^{22}$ Belucis ${ }^{23}$ Simis ${ }^{24}$ Tomeza ${ }^{25}$ Cornazo ${ }^{26}$ Talauo ${ }^{27}$ Cordario ${ }^{28}$ quatrior ${ }^{29}$ sex ${ }^{30}$ Boneli ${ }^{31}$ Mullieres ${ }^{32}$ vivariis ${ }^{33}$ caldariis ${ }^{34}$ ductibus ${ }^{35}$ aliorum hominum] aliorum omnium hominum ${ }^{36}$ XVII kalendas] dizima septima calendas $\left.{ }^{37} \mathrm{XL}^{\mathrm{n}} \mathrm{III}\right]$ tertiadecima, por evidente omissão da leitura da aspa do $X{ }^{38}$ elegimus ${ }^{39} \mathrm{et}{ }^{40}$ maledictionibus ${ }^{41}$ Raimundus celestis] Raymundus divinae celestis ${ }^{42}$ compunctus ${ }^{43}$ Infanta ${ }^{44}$ Sançia ${ }^{45}$ Adephonsus ${ }^{46}$ Ariensis ${ }^{47}$ Jannes ${ }^{48}$ Gudesteriz ${ }^{49}$ Gundisalbus ${ }^{50}$ Froila ${ }^{51}$ Omite comes ${ }^{52}$ Pelagius] presbiti conf. ${ }^{53}$ Ego Arnundariz. ${ }^{54}$ Adiarius ${ }^{55}$ Omite canonice ${ }^{56}$ Gudsteris ${ }^{57}$ Lorepa ${ }^{58}$ Gudsteris ${ }^{59}$ Guntadix ${ }^{60}$ alia ${ }^{61}$ fecit ${ }^{62}$ Adephonsus ${ }^{63}$ Morrazo ${ }^{64}$ Adriz ${ }^{65}$ Cresconio Citis] Creston poatis ${ }^{66}$ Ticinus ${ }^{67}$ Ticinus ${ }^{68} \mathrm{Cresconis}$ ] Ores conig ${ }^{69}$ Gudestorius ${ }^{70}$ Ordonis ${ }^{71}$ Aluiens Cengoibus] Alvarus Cenonis. 


\section{COMO CITAR ESTE ARTIGO}

\section{Referência electrónica:}

ESTEFÂNIO, Abel - "Proposta de aclaração do "pacto sucessório" à luz de novos dados".

Medievalista [Em linha]. Nº16 (Julho - Dezembro 2014). [Consultado dd.mm.aaaa]. Disponível em http://www2.fcsh.unl.pt/iem/medievalista/MEDIEVALISTA16। ISSN 1646-740X.

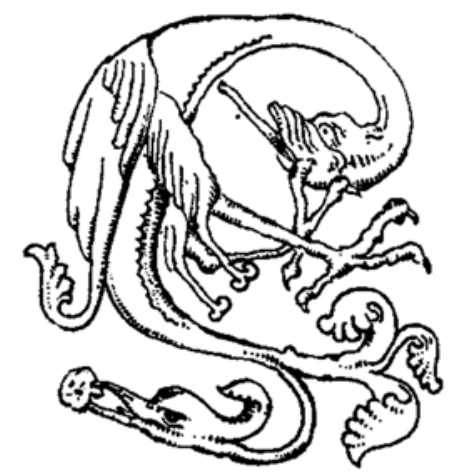

